\title{
USO Y TENENCIA DE LA TIERRA... FACTORES HISTÓRICOS Y PLANES DE ORDENAMIENTO TERRITORIAL - VEREDAS BARCELONA, COCUY Y ZURÍA - VILLAVICENCIO, COLOMBIA ${ }^{1}$
}

\section{USE AND TENURE OF THE LAND... HISTORICAL FACTORS AND TERRITORIAL ORDER PLANNING - VILLAGES BARCELONA, COCUY AND ZURÍA - VILLAVICENCIO, COLOMBIA}

Juan Manuel Ochoa Amaya²

\section{Resumen}

El territorio de las veredas Barcelona, Cocuy y Zuría en Villavicencio ha venido manifestando cambios en su uso y tenencia en los últimos 20 años, conllevando a una ocupación desordenada y por fuera de los estándares establecidos dentro del Plan de Ordenamiento Territorial (POT). Situación que va en contra de los instrumentos técnicos y normativos que permiten ordenar el territorio, y que obedece principalmente al crecimiento poblacional por ocupación desordenada del suelo.

Los resultados presentados en este artículo emanan de un trabajo de investigación desarrollado con el apoyo de la Universidad de los Llanos, donde se analizan los cambios en el uso y tenencia del suelo rural de tres veredas de Villavicencio, con la finalidad de determinar las consecuencias ambientales, económicas y sociales, derivadas de una inadecuada planificación del territorio. Para ello se aborda información histórica referente a la ocupación de Villavicencio, decantando finalmente en el análisis de los POT en cuanto a uso y tenencia del suelo y en relación con la sostenibilidad ambiental y los factores históricos que influyen en el uso de la tierra. Así la metodología implementada fue cualitativa-cuantitativa, en la que se incorporó análisis a las encuestas y entrevistas, a través de la ayuda de SPSS y NVIVO, para interpretar los datos obtenidos de una manera más real y profunda.

Palabras clave: Territorio; Uso de la Tierra; Tenencia de la Tierra; Medio Ambiente; Planificación Territorial.

\begin{abstract}
The territory of the Barcelona, Cocuy and Zuría Villages in Villavicencio has been showing changes in its use and tenure in the last 20 years, leading to a disorderly occupation and outside the standards established in the Territorial Planning Plan (POT). Situation that goes against the technical and normative instruments that allow to order the territory, and that mainly obeys to the population growth by disordered occupation of the ground.

The results presented in this article emanate from a research work developed with the support of the University of the Llanos, where the changes in the use and possession of the rural land of three villages of Villavicencio are analyzed, in order to determine the environmental consequences, economic and social, derived from an inadequate planning of the territory. For

\footnotetext{
${ }^{1}$ Este artículo es el resultado de la investigación titulada: TENENCIA Y USO DEL SUELO EN LAS VEREDAS BARCELONA, COCUY Y ZURÍA, UN ESTUDIO DE CASO AMBIENTAL, desarrollada desde el 10 de agosto de 2015 hasta el 02 de febrero de 2017, por el grupo de trabajo TRADO, adscrito al grupo de investigación Territorio y Ambiente, en la Universidad de los Llanos de la ciudad de Villavicencio, departamento del Meta, Colombia.

2 Doctorando en Estudios Territoriales. Docente de la Universidad de los Llanos, Colômbia. E-mail: juan.ochoa@unillanos.edu.co
} 
this, historical information regarding the occupation of Villavicencio is addressed, finally deciding on the analysis of the POTs in terms of land use and tenure and in relation to environmental sustainability. Thus the methodology implemented was qualitative-quantitative, in which analysis was incorporated to the surveys and interviews, through the help of SPSS and NVIVO, to interpret the data obtained in a more real and deep.

Keywords: Territory; Land Use; Land Tenure; Environment; Territorial Planning.

\section{INTRODUCCIÓN}

Teniendo en cuenta que el territorio representa un papel fundamental en el desarrollo económico y social de un determinado país o región, su concepto no se debe restringir a un espacio geográfico o delimitación administrativa del Estado, sino que se debe concebir como un ente activo y decisivo que requiere de una adecuada planificación, que garantice el uso adecuado de los recursos locales. Bajo esta premisa el buen control del proceso de ocupación del territorio y el adecuado uso y tenencia de la tierra se convierten en variables fundamentales de la planificación territorial para encaminar el territorio hacia el desarrollo.

Sin embargo, en Villavicencio el proceso de ocupación del territorio se ha presentado de forma desordenada, y los planes de ordenamiento territorial diseñados como un instrumento técnico y normativo para ordenar el territorio urbano y rural no han sido eficaces a la hora de controlar el crecimiento poblacional y los procesos de ocupación del suelo, desencadenando una serie de consecuencias ambientales, económicas y sociales negativas para el desarrollo sostenible de la ciudad, y en especial el suelo rural que cada vez se ve más implicado en las tendencias de urbanización de la ciudad, atentando contra su función principal que es proveer los servicios ambientales y las materias primas al territorio.

Por tal motivo el presente estudio se centra en analizar los cambios en el uso y tenencia del suelo rural de la ciudad de Villavicencio, específicamente las veredas Barcelona, Cocuy y Zuría, de tal manera que se pueda determinar las consecuencias tanto ambientales como económicas y sociales que trae consigo una inadecuada planificación territorial.

Durante el análisis se aborda el proceso histórico de ocupación de Villavicencio y las políticas que se han implementado en los Planes de Ordenamiento Territorial para controlar el uso y la tenencia del suelo y promover la sostenibilidad ambiental, de tal manera que se pueda identificar con mayor claridad las causas y consecuencias del uso y la tenencia que se ha dado al suelo rural teniendo siempre como base de investigación las veredas antes mencionadas. 


\section{MARCO TEÓRICO, USO Y TENENCIA DE LA TIERRA}

El siglo XIX se caracterizó por ser un periodo de grandes cambios. Desde el punto de vista económico y social se produce el fin de la economía feudal y de la sociedad estamental, que da paso a un sistema económico capitalista y a la sociedad de clases.

El modelo de desarrollo capitalista y el apogeo de la industrialización traen consigo un periodo de transición hacia el ciclo demográfico moderno, caracterizado por mantener altas tasas de natalidad y el descenso constante de los índices de mortalidad a causa de las mejoras en la alimentación, la higiene y los nuevos avances en la industria farmacológica. Estos factores provocaron que la población mundial creciera rápidamente y en un siglo pasara de 978 a 1.650 millones de habitantes; adicionalmente, los avances en el transporte y las comunicaciones favorecieron los movimientos migratorios, destacándose los desplazamientos del campo a las ciudades que crecerían de manera acelerada sin planificación.

En América Latina las tendencias migratorias tendrían un patrón similar, con mayor notoriedad en el siglo XX, más específicamente entre 1950 y 1960, cuando la inclinación de los países latinoamericanos de sustentarse en el sector terciario y la alta tasa de endeudamiento los llevó a una crisis. De acuerdo a Calvet Puit (2005) este acelerado crecimiento urbano y la proliferación de ciudades dieron lugar a un modelo de asentamiento caracterizado por la concentración de la población y un crecimiento desordenado de las ciudades.

La alta urbanización generó un proceso acelerado de crecimiento en las periferias urbanas (zonas suburbanas y de expansión urbana) como respuesta a la necesidad de encontrar territorios localizados lejos de la congestión y contaminación de la ciudad con mejores condiciones ambientales. Salvador Rueda (2009) describe de manera clara este tipo de procesos:

El resultado es una ciudad que se difumina en el campo ocupando áreas cada vez más extensas (en ocasiones regiones enteras). Es la ciudad difusa que tiene de todo, pero disperso, separado funcionalmente (la universidad, la industria, las áreas comerciales, la residencia, las oficinas, etc. Se separan físicamente) y segregado socialmente, uniendo las partes a través de una densa red de carreteras y vías segregadas de transporte privado. Esta forma de proceder multiplica el consumo de suelo, energía y materiales. (Pág. 2).

De esta manera las nuevas dinámicas de ocupación del territorio generaron una serie de transformaciones en la organización espacial de lo urbano y lo rural. A finales de 1960 cuando se hacía referencia a la periferia urbana, se consideraba un espacio subordinado al ámbito central de la ciudad, muy lejano, pero fuertemente implicado con los componentes 
rurales adyacentes (AGUILAR A. , 1999). En la actualidad, prevalece un nuevo modelo de expansión urbana en el contexto espacial de la metrópoli y de la ciudad-región. La globalización, mediante la expresión territorial de las megaciudades, ha favorecido un proceso de dispersión urbana, expresado en el desarrollo de nuevas y diversas actividades económicas (sobre todo servicios), así como el desarrollo de infraestructura urbana y del transporte, además de la desconcentración de funciones hacia ciudades medias y pequeñas, o bien, hacia espacios rurales o urbano-rurales dentro de la región (AGUILAR A. G., 2006).

Los procesos de urbanización han sido producto de un crecimiento urbano improvisado que se presenta con más frecuencia en las ciudades medianas o intermedias. Algunas ciudades han superado el límite de urbanización, en perjuicio la calidad de vida de la población que allí habita, por lo cual, la expansión del perímetro urbano de las ciudades sobre el rural ha marcado aún más los procesos no ordenados de expansión, aumentando los riesgos ambientales y sociales.

El avance del crecimiento urbano ocurre ocasionalmente sobre espacios históricamente rurales, donde se encuentran asentadas las comunidades campesinas con cultura y procesos propios, con una forma específica de vincularse con la ciudad y el espacio inmediato que le rodea ha desarrollado nuevas formas de vivir y relacionarse, de apropiarse y de aprehender los espacios periféricos y los rurales en torno a la ciudad (ARIAS, 2005). Esta expansión ha traído un nuevo concepto que constituye una transición entre lo urbano y lo rural denominado suburbanización.

El espacio suburbano se caracteriza por estar aún dominado por actividades rurales agropecuarias y forestales, pero ampliamente transformado por las construcciones, el consumo de bienes y servicios y estilos de vida cada vez más afines a la ciudad. Estos primeros territorios colonizados por la dispersión de la ciudad, muchas veces carecen de una ordenación y planeamiento. Como refiere CALVET PUIG (2005, pág. 50) "la expansión muchas veces ha sido más fruto de una demanda urgente que de un proceso razonado y previsto de descentralización, y quizá por esto estos crecimientos muchas veces han estado al margen de las infraestructuras necesarias, tanto para las actividades de las personas como para las de las industrias".

\section{Modelos de crecimiento urbano}

Las ciudades representan para muchos individuos y familias soluciones productivas y mejores condiciones de vida, sin embargo, en su configuración se presentan retos por la 
manera en que crecen y se organizan. El modelo de crecimiento urbano puede generar bienestar o perjuicios a los habitantes, debido a las condiciones de eficiencia en aprovechamiento del suelo, provisión de servicios, transporte, espacios públicos e interacción comunitaria.

El crecimiento puede darse entonces de dos formas opuestas: en modelos de ciudad difusa o compacta. La primera se desarrolla, se planifica y desarrolla su infraestructura de forma ineficiente, con baja competitividad, generando pérdidas económicas y sociales. En este tipo de ciudades se consume más energía y materiales para obtener los mismos resultados. En este tipo de estructuras, se pierde el sentido de ciudad, para dar paso a asentamientos urbanos donde las redes de comunicación y las vías vehiculares prevalecen por encima de los espacios para caminar.

La segregación espacial se traslada a la dimensión socioeconómica y esa forma de crecimiento inconexo genera a su alrededor más expansión urbana de la misma naturaleza. Surgen núcleos privilegiados por su nivel de renta, lo que aumenta la segregación y desconexión.

Los intentos que se realizan en este tipo de ciudades por mejorar la eficiencia perdida, solo expanden la problemática a superficies mayores, al buscar resolver la ineficiencia de la red.

A diferencia del modelo difuso, en el modelo compacto el espacio público y los corredores peatonales cobran máxima relevancia, como lo expresa Salvador Rueda (2009):

Ese tipo de ciudad compacta y densa con continuidad formal, multifuncional, heterogénea y diversa, es un modelo que contribuye al aumento de la complejidad de los sistemas que atienden eficazmente las necesidades de la población y conllevan a una plataforma económica competitiva, al mismo tiempo que se ahorra suelo, energía y recursos materiales, en donde se preservan los sistemas agrícolas y naturales, con un nivel de explotación sostenible (p. 8)

Algunos autores afirman que en su mayoría las ciudades no llegan a aplicar a ninguno de los dos modelos mencionados anteriormente, para el caso de las ciudades intermedias se acercan más al modelo de ciudad difusa.

El desarrollo urbano sostenible es un pilar fundamental en el modelo de ciudad compacta, el concepto de sostenibilidad tuvo su origen paralelamente con la preservación de la naturaleza, pero fue a finales del XX cuando el tema tomo relevancia y se consolido, "el concepto de desarrollo sostenible fue introducido en 1987 en el informe de la Comisión de las Naciones Unidas para el Medio Ambiente y Desarrollo, y se entendía como un proceso de 
progreso económico armonioso capaz de satisfacer los principios de justicia social y responsabilidad ambiental". (BANCO INTERAMERICANO DE DESARROLLO BID, 2011).

La Comisión de Desarrollo y Medio Ambiente definió el desarrollo sostenible en los siguientes términos "Está en manos de la humanidad asegurar que el desarrollo sea sostenible, es decir, asegurar que satisfaga las necesidades del presente sin comprometer la capacidad de las futuras generaciones para satisfacer las propias" (COMISIÓN DE DESARROLLO Y MEDIO AMBIENTE, 1987).

Este concepto ha tenido diferentes definiciones y algunas han sido incorrectas o poco profundas; para 1992 Naciones Unidas en la Cumbre de Rio dio a conocer un avance importante en el tema y profundizando en lo normativo (Sánchez, 2007):

Proponiendo la total integración entre desarrollo y medio ambiente y enfatizando en ciertos principios éticos que debieran guiar, universalmente, la gestión de los problemas ambientales y del progreso humano: la cooperación internacional en políticas ambientales y de desarrollo y la responsabilidad diferenciada en el impacto ecológico y social. Asimismo se insistió en que no era posible un desarrollo humano sostenible si no están garantizados unos derechos fundamentales, entre ellos: (a) el derecho soberano de cada estado a hacer uso de sus propios recursos, siempre y cuando se respeten los límites a su explotación; (b) el mantenimiento de un marco democrático; y (c) la conservación de los valores culturales particulares de cada región o comunidad. (p. 157).

Desde este enfoque, el desarrollo sostenible no es solo visto como la producción y acumulación de bienes en el largo plazo, sino que también toma en cuenta lo económico, social y la protección ambiental como los pilares fundamentales de este. Para las Naciones Unidas debe estar enfocado a mejorar la calidad de los habitantes y en la planeación territorial, bajo los principios de respeto por los derechos humanos, la equidad y la sostenibilidad basándose en tres principios fundamentales: desarrollo social incluyente, sostenibilidad ambiental y desarrollo económico incluyente. (Programa de las Naciones Unidas para el Desarrollo, 1998)

Un desarrollo que no solo genera crecimiento, sino que distribuye sus beneficios equitativamente, que regenera el medio ambiente en vez de destruirlo y que potencia a las personas en vez de marginarlas, ampliando sus opciones y oportunidades y permitiéndole su participación en las decisiones que afectan sus vidas (Pág. 15)

\section{Desarrollo Local}

El desarrollo local se define como (Barquero, 2000)

Un proceso de crecimiento y cambio estructural de la economía de una ciudad, comarca o región, en el que se pueden identificar, al menos, tres dimensiones: una económica, caracterizada por un sistema de producción que permite a las empresas locales usar, eficientemente, los 
factores productivos, generar economías de escalas y aumentar la productividad a niveles que permitan mejorar la competitividad en los mercados; otra sociocultural, en que el sistema de relaciones económicas y sociales, las instituciones locales y los valores, sirven de base al proceso de desarrollo, y otra político-administrativa en que las iniciativas locales crean un entorno local favorable a la producción e impulsan el desarrollo sostenible. (p. 6).

(Caraggio, 1999) Afirma que:

Todo proceso de desarrollo local debe sustentarse desde la perspectiva de condiciones endógenas e integrales, que movilicen los recursos económicos sin desmejorar el ambiente, las capacidades y las voluntades individuales y colectivas de la sociedad local, generando un espíritu de dinamismo, innovación y de expectativas para lograr que los cambios deseables sean posibles.

Otros autores afirman que no existe una definición de desarrollo local única, según

(Pietro, 2001)

No existe una definición de desarrollo local única ni excluyente, por lo que presenta algunas consideraciones al respecto; la de Boisier quien señala que existe una confusión en su significación, ya que es una práctica sin teoría y tiene por lo menos tres puntos de origen: como respuesta a la crisis macroeconómica y al ajuste de los países, por otro lado como dialéctica global/local, y en última instancia, como una expresión lógica de regulación horizontal, presenta por igual la propuesta de Vásquez, quién lo define remarcando el aspecto económico y de alianzas entre sectores.

Con la descentralización los entes territoriales han pasado de tener un rol pasivo a un rol activo, en donde la planificación territorial es el eje principal.

\section{Planificación territorial}

La planificación territorial es fundamental para la construcción de una ciudad sostenible y equilibrada. Una buena planeación del territorio provee calidad de vida, suministro óptimo de los servicios e infraestructura suficiente para el desarrollo de la ciudad, así como la conservación del medio ambiente.

Así lo demuestra CALVET PUIG (2005) en uno de sus principales trabajos sobre urbanismo, donde evidencia que aquellos municipios donde ha existido una falta de anticipación urbanística son precisamente los que presentan mayores desequilibrios, mientras las ciudades que tienen el índice de actividad urbanística más alto son las ciudades que más destacan en las variables favorables al municipio como la renta, centros escolares, residencias para mayores, actividad económica, etc.(Citado en FERRERO, 2010, pág.49). 
En su investigación CALVET PUIG (2005) concluye señalando que "la no previsión del futuro en la evolución del suelo de la ciudad puede llevar a espacios degradados, donde la intervención privada se ha retirado y donde solo la intervención pública puede recuperar la zona después de múltiples intervenciones urbanísticas, sociales y de todo tipo" (p. 291).

Por su parte, FERRAS SEXTO (2000) también indica que la investigación y planificación de la urbanización podría llegar a significar, en el marco de políticas territoriales bien definidas, un desarrollo regional equilibrado y unas nuevas relaciones entre la ciudad y el campo.

El incremento del área urbana debe basarse en la planificación y considerar todas las afectaciones que se pueden generar desde el punto de vista ambiental, social, económico y cultural; el proceso de planificación debe ser un proceso holístico donde los planes y programas del gobierno consideren al suelo no como un instrumento susceptible a comercializarse gracias a la expansión urbana sino como un elemento indispensable para la vida humana. Como lo indica URBANO (2013) el desarrollo urbano requiere de una planificación adecuada y cuidadosa con la finalidad de normar y evitar o disminuir impactos negativos futuros; debe ser sustentable donde puedan conservarse los recursos naturales.

El equilibrio de un determinado territorio se basa en el desarrollo socioeconómico en armonía con la preservación de los recursos. La urbanización sustentable promueve un crecimiento económico que estimula la calidad de vida de las personas y fomenta la equidad con los recursos naturales de manera perdurable. Es indispensable que el Estado como ente planificador cuente con una visión más amplia respecto a lo que implica el desarrollo territorial de tal manera que diseñe políticas encaminadas a edificar ciudades sustentables y equilibradas que respeten el medio ambiente y colaboren con la preservación de los recursos naturales.

\section{ASPECTOS HISTÓRICOS DEL USO Y TENENCIA DE LA TIERRA EN COLOMBIA}

Desde el enfoque histórico para el desarrollo del trabajo se realiza un recorrido en el proceso de ocupación del territorio reconociendo los aspectos políticos y administrativos que han influido en este proceso; desde el ámbito nacional - regional para así enfocarse en lo local y contextualizar a través del tiempo la realidad actual que se presenta en la ciudad de Villavicencio con los procesos de planeación en el uso del espacio urbano y rural. 


\section{Colombia, de la época colonial a la República}

En el marco del colonialismo la planificación y administración del territorio americano, se caracterizaron por ser centralizadas, con un sistema heredado de los europeos mediante el cual habían sometido a otros pueblos, aspecto que no fue diferente para los territorios de la Nueva Granada. El interés español por la conquista del territorio estuvo orientado en un modelo extractivista de acumulación de capital, a través de la apropiación de la riqueza social y los recursos de los pueblos indígenas que perduró por más de 300 años, dejando huellas en la organización económica, territorial, política y social.

La apropiación del territorio por parte de la Corona Española estuvo soportada por el avance en sus conquistas, en donde se encomendaba a los conquistadores la fundación de ciudades en puntos estratégicos para ejercer el poder y obtener mayores beneficios, como lo expresa (Hardoy J. E., 1973):

En el periodo con mayor auge en la fundación de ciudades, se crearon centros administrativos, puertos, centros mineros y agrícolas, presidios y centros militares, centros de catequización y un sin número de asentamientos menores con el fin de ampliar el dominio político y económico por parte de la corona. (p. 33).

Otros poblamientos fueron fundados por iniciativa propia del conquistador que luego recibía la aprobación por parte del reino; a cambio de su logro, los conquistadores recibían parte de las tierras conquistadas, riquezas y poder sobre la población allí establecida.

Los asentamientos más importantes de la época colonial fueron fundados formalmente, muchos de ellos se conservan hoy en día como ciudades capitales o importantes centros económicos. Según (Hardoy J. , s.f.)

A comienzos del siglo XIX los españoles construyeron en sus colonias de América un gran número de ciudades, villas y asentamientos humanos de toda clase para servir a los objetivos de su política imperial. Su número y listado no han sido nunca determinados, pero podemos asumir que fueron millares. Muchos fueron abandonados, otros fueron trasladados una, dos, tres o más veces hasta encontrar la localización y el sitio más adecuados, pero el número de los que perduraron hasta nuestros días es realmente notable y entre ellos se encuentran casi todas las capitales nacionales y regionales de los países de América Latina de lengua española. (p. 1)

En el avance de la conquista como se ha mencionado, se impuso una estructura para dominar y canalizar el flujo de riquezas hacia la corona española, aspecto que produjo el fortalecimiento de algunos grupos de poder al interior del territorio; dicho proceso estuvo inicialmente conformado por españoles para luego pasar a manos de los criollos, quienes con 
menos derechos que aquellos nacidos en la madre patria, se convertirían en los precursores de la independencia.

La transición a la época republicana, ocurre con los territorios delimitados por la estructura planteada por el esquema colonial, como lo afirma (Fajardo Montaña, 1998) “El incipiente Estado nacional arrastró consigo problemas derivados de las tensiones de grupos hegemónicos locales y regiones administrativas en competencia, dando lugar a obstáculos de integración funcional de estos territorios entre sí" (p. 32). Inicialmente la debilidad del Estado como se mencionó anteriormente generó que se mantuvieran las formas de organización heredadas de la Colonia, definidas como estado-región y provincia en donde se presentaba una notoria desarticulación entre los territorios; a pesar de los esfuerzos por generar la articulación entre estos, solo hasta 1886 constitucionalmente se reivindicó el carácter unitario en la constitución y nacieron los entes territoriales como hoy los conocemos, con los departamentos, las intendencias, las comisarías, los municipios y los distritos municipales como unidades básicas. Con la reforma de 1968 en la constitución en cuanto al ordenamiento territorial se reafirmó la división administrativa existente, a nivel departamental crearon las asociaciones de municipios y a nivel municipal las juntas administradoras locales, y se encuentra que "a partir de allí se consolidó en el nuevo Estado, con las reformas constitucionales de 1936 y 1968; naciendo así la triada nación, departamento y municipio" (BORJA, 1996).

Los siglos XIX y XX fueron un periodo de cambios en la estructura político-administrativa de la nación. Con la Constitución Política de Colombia de 1991 se generaron cambios en el proceso de descentralización y regionalización administrativa, política social y económica en donde se reconocen como entidades territoriales: los departamentos, los distritos, los municipios y los territorios indígenas; además, queda abierta la posibilidad para que regiones y provincias puedan formarse adoptando personería jurídica, autonomía y patrimonio propio. La nueva división de los territorios tenía como objetivo principal lograr el equilibrio entre la independencia político-administrativa del Estado Unitario y los entes territoriales. (ESTUPIÑÁN, 2012)“La Constitución Política de Colombia de 1991, definió el ordenamiento territorial y la descentralización como "pilares del proceso de formación del estado" (p. 47).

\section{Poblamiento y relevancia de la región Orinoquia}

Dando una mirada al poblamiento región de la Orinoquia desde los tiempos coloniales se encuentra que el entorno natural y la hostilidad de los nativos, representó una barrera inicial 
para el avance colonizador y sus intereses. Este obstáculo afectó la gobernanza del territorio y se mantuvo presente desde la Colonia, hasta finales de siglo XX.

El mismo Codazzi, en su condición de director de la Comisión Corográfica, consideró como los dos más grandes obstáculos para el desarrollo de la Provincia de Casanare, la existencia de los indios y las condiciones climáticas del territorio. Estimaba que "para hacer retroceder a estos bárbaros se necesitaría de una gran población, la que no podía llegar sino paulatinamente." (FAJARDO MONTAÑA, 1998, p. 54)

Bajo este paradigma se legitimó la reducción de la población indígena de esta parte del país y la enajenación de estas comunidades en sus propios territorios. La colonización de esos territorios se dejó en manos de las misiones Jesuitas, que desde 1620 hasta 1767 llegaron a convertir al catolicismo a miles de indígenas de los Llanos, con métodos desde los más filantrópicos hasta los más aberrantes. Cuando los nativos estaban sometidos se les enseñaban las labores propias de las haciendas, como lo menciona (Fajardo Montaña, 1998).

Una vez adoctrinadas las comunidades, se iniciaba la enseñanza de labores agrícolas y ganaderas, dando origen con ello a la organización de un complejo socio-económico y la formación de pueblos y haciendas en una próspera economía durante los siglos XVII y XVIII. (p. 78).

Los Jesuitas tuvieron asentamientos importantes en lugares como la hacienda Apiay, donde tenían miles de cabezas de ganado. Allí ofrecían pastos y descanso para el ganado, posada y comida para los arrieros que provenían del llano adentro, antes de continuar su camino hacia Bogotá. Su presencia en la región se mantuvo hasta 1767 cuando el Rey de España Carlos III los expulsó, recuperando con ello las haciendas Apiay, Caribabare, Crano, y Patute. La expulsión definitiva se dio con la salida de la compañía de Jesús, por mandato del entonces presidente José Hilario López. (Jaramillo, 1997) Afirma:

Ciertamente, el episodio que resultó más relevante en el choque de las dos potestades durante el gobierno de López resultóser el de la expulsión de los miembros de la Compañía de Jesús, en el cual el mismo López actuó en medio de grandes dudas, reveladoras de las diferentes corrientes de presión en las que se encontró durante su mandato. Como en ninguna otra decisión alrededor del gobierno, se formó un remolino a propósito de esta decisión. (p. 26)

Posterior a la expulsión de los Jesuitas se buscó la repoblación de la región, sin embargo, aspectos como la barrera representada por los indígenas, las condiciones naturales y el riesgo para la salud que implicaba para los colonos migrar a los Llanos Orientales, retrasaron la colonización. (Barqna, Gomez, \& Dominguez, s.f.) Mencionan que:

Las guerras de Independencia significaron una pérdida enorme para la Orinoquia, ya que se destruyeron tres siglos de formación territorial que 
se habían logrado por medio de una extrema crueldad y sacrificio. Durante el período colonial el Estado español y las Misiones jesuíticas lograron crear pueblos de tipo europeizante, abrir haciendas ganaderas, establecer la navegación en numerosos ríos y trazar caminos para el comercio. Una enorme riqueza social estructurada con el sudor y la destrucción cultural de las comunidades indígenas de la región que, mal que bien, ya hacían parte de esa nueva realidad.

Para el siglo XX los migrantes llegaron a esta región en búsqueda de oportunidades económicas, por el atractivo que género el descubrimiento de yacimientos de petróleo en los departamentos del Meta y Casanare, por ser considerada la última frontera agrícola que tiene el país, un territorio de oportunidades potencial para la explotación de recursos naturales y con grandes extensiones de tierras. El gobierno nacional reconoce la importancia que la región Orinoquia representa actualmente para el país, por lo cual tiene retos en cuanto a planeación, infraestructura y ordenamiento territorial para cumplir las expectativas planteadas, el Departamento Nacional de Planeación afirma que:

En el año 2020, la región será un territorio integrado, fronterizo, biodiverso, generador y centro de desarrollo de la economía nacional y regional, soportado en su capital humano, su fortaleza empresarial, su innovación tecnológica y su generación de conocimiento en actividades con alto valor agregado, garantizando la productividad y competitividad para una inserción exitosa en el entorno nacional e internacional. (DNP, 2007, p. 13)

\section{Villavicencio, proceso de ocupación}

En el territorio que hoy es Villavicencio, el proceso de ocupación estuvo acompañado de transformaciones geográficas y demográficas ligadas a cierto grado de violencia. En medio de la adquisición de tierras en el siglo XIX, los colonos despojaron a los indígenas nativos de sus tierras o los intercambiaban por armas y herramientas, es así que:

Las expediciones de los conquistadores en busca del Dorado y los colonizadores posteriormente han tenido un efecto desintegrador del grupo y la tierra sobre sociedades indígenas: hicieron esclavos a los indios y no tuvieron escrúpulos para azotar, castigar, maltratar o asesinar a los nativos; los indios fueron destruidos y arruinados. En su personalidad, su familia, su comunidad, y los despojaron de sus tierras. Gómez citado en (Ojeda, 2000, p. 83)

Sin embargo, el proceso de ocupación de tierras en Villavicencio no se dio de manera planeada, surgió de forma espontánea donde inicialmente era considerado un lugar de paso para comerciantes que efectuaban transacciones ganaderas entre San Martín y Santa Fe de Bogotá, por dos razones principales, por su ubicación geográfica estratégica y el legado que dejaron los jesuitas, como lo menciona (ESPINEL, 1989)“Villavicencio tuvo su origen a partir de 
la colonización espontanea que se generó en su entorno debido al descanso que tomaban los comerciantes que efectuaban transacciones ganaderas entre Santa Fe de Bogotá y San Martín, antes de iniciar nuevamente su jornada hacia la cordillera o de la cordillera hacia el llano " ( $p$. 134).

A principios del siglo XX, la mirada de algunos comerciantes se fijó en Villavicencio visualizando este territorio con oportunidades para invertir, (Ojeda, 2000), afirma:

La concentración de la propiedad rural, la disponibilidad de capital y las influencias políticas y económicas permitió forjar 27 grandes haciendas: siendo Emiliano Restrepo dueño de 7, José Bonnet de 3, Sergio Convers, Nicolás Castro y los hermanos Vásquez cada uno de a dos. (p. 45)

La historiadora Jane Rausch lo ratifica afirmando:

Villavicencio era una aglomeración de ranchos levantados con calles trazadas en ángulos rectos, la mayoría de los 600 habitantes que existían para esta época cultivaban la yuca, el plátano y el arroz, o recogían el ganado que vagaba en los llanos. Las casas eran casi todas de bahareque o madera con techo de palma, tres años más tarde la región experimentaría el progreso capitalista propio del momento a través del desarrollo agropecuario y comercial de las haciendas, entre estas sobresalía la hacienda el Buque propiedad de Sergio Convers que llegó a tener 80 mil cafetos cuyo producto fue exportado, aquí una muestra de relevancia que empezó a experimentar la Orinoquia para el país, para 1874 en la región había más de un millón de cafetos y 120 mil cabezas de ganado, por lo cual en 1869 se inició la construcción de la vía que comunicaría a Bogotá con Villavicencio para facilitar el comercio. (Rausch, 2011, p. 25)

Para la década comprendida entre 1899 y 1909 la Guerra de los Mil Días, la separación de Panamá y la dictadura de Rafael Reyes, periodo conocido como el quinquenio donde se constituyó la consolidación de la república moderna, hechos que marcaron la historia del país, afectaron el sector económico de Villavicencio e influyeron en los conflictos que surgieron a partir de las diferencias partidarias y reclamación de mejores condiciones para la población campesina, generando los primeros movimientos campesinos armados que se enfrascaron principalmente en los territorios de San Martín, Casanare y Arauca. En 1890, el 28 de enero se presentó en la ciudad un devastador incendio que también afectó el progreso de Villavicencio, como lo menciona (RAUSCH, 2011) "aunque en el pasado ocurrieron otros incendios en Villavicencio, la magnitud de este último obligo a James Córdoba, Secretario de Gobierno de Cundinamarca, a asignar una suma de 2.000 pesos de fondos departamentales, para contribuir a la reconstrucción del pueblo" (p. 44).

Pese al estancamiento que vivió la ciudad de Villavicencio a partir de los hechos mencionados anteriormente, para finales del siglo XX, la ciudad se convirtió en un refugio y una 
oportunidad de vida para los habitantes desplazados del centro del país que voltearon su mirada hacia los llanos gracias a la fertilidad de los suelos, el agua abundante y la seguridad frente a las inundaciones con la que contaba por sus ventajas geográficas; convirtiéndose la ganadería en la actividad económica principal. "Para esta misma época se incrementó la violencia en los llanos, a causa del fenómeno del narcotráfico y la expansión de los grupos armados campesinos que dieron como resultado las guerrillas móviles el germen del que en 1964 nacieron las FARC" (OJEDA, 2000, p. 108)

El desarrollo económico y político de la ciudad se fue presentando progresivamente, aunque con algunas situaciones mencionadas anteriormente propias del territorio que estancaban los procesos y generaba desinterés del gobierno central. Durante la republica liberal de 1930 a 1949, con la administración de Olaya Herrera y Alfonso López Pumarejo se expidieron políticas en pro de impulsar el crecimiento del país, por medio de innovaciones políticas sociales nacionalistas se propusieron el objetivo de industrializarlo. A partir de las reformas de Pumarejo se construyó un programa de gobierno denominado Revolución en Marcha, con el interés de llevar la gobernabilidad a todas las zonas apartadas y Villavicencio fue una de las zonas priorizadas, la mayoría de autores coinciden en que fue el primer presidente que mostró interés en el desarrollo del Meta con sus políticas territoriales.

Por otra parte, la culminación de la autopista Bogotá - Villavicencio para el año 1990 impulsó el potencial de Villavicencio; “ya se sabía con anterioridad la importancia de la ciudad como un polo de desarrollo, constituyéndose a la vez en el principal centro de consolidación de carga de la región" (MATUS, 1997, pág.88) de allí la necesidad de empezar la construcción de esta importante autopista. En palabras de la historiadora Jane Raush:

Desde 1922, el Ministerio de Obras Publicas dio comienzos a las obras de la carretera para hacerla transitable para automóviles y camiones. Para 1926, quinientos convictos reconstruyeron el tramo de $30 \mathrm{~km}$ entre Bogotá y Chipaque. Para 1929 se agregaron otros $17 \mathrm{~km}$ y los $78 \mathrm{~km}$ se terminaron entre 1930 y 1936. (Rausch, 2011, p. 44)

Dada la importancia que esta vía ha representado para el país se le han realizado nuevas inversiones, la más reciente la doble calzada Bogotá - Villavicencio buscando que la nueva vía sea un aporte directo al mejoramiento de la vida de la comunidad local, regional y nacional. "La doble calzada optimizará el recorrido, brindando mayor seguridad y reduciendo significativamente el tiempo de desplazamiento entre ambas ciudades a más de 25 minutos" (COVIANDES, 2015).

La mirada del país en los últimos años se ha enfocado en los llanos considerándolo la última frontera agrícola con la que cuenta el país y resaltando la importancia de generar 
políticas que impulsen la productividad económica en esta zona, lo que ha generado que Villavicencio sea una ciudad llamativa para la llegada de nuevos inversionistas.

La importancia progresiva que ha tenido la ciudad ha traído consigo implicaciones en el aumento poblacional que históricamente se ha presentado de forma acelerada, según Informe Intendente del Meta 1925 citado (Rausch, 2011, p. 83)

La población de Villavicencio y de la intendencia aumentó a pasos agigantados a pesar de la amenaza de enfermedades y la elevada mortalidad. Entre 1904 a 1918 el número de habitantes creció de 3.315 a 4.774 incremento del $44 \%$. Al mismo tiempo que se duplicó la población regional: de 4957 a 11671.

Los fenómenos que han generado procesos de poblamiento mencionados anteriormente han generado que el crecimiento de la ciudad no haya sido organizado como lo plantea (Baquero, 2011, citado en Raush 2011)

En una perspectiva mayor a cuatro décadas de conciencia sobre la ciudad y de su extensa área de influencia, se percibe la sintomatología de un crecimiento sin control, sin orden alguno, en áreas inadecuadas y sin vestigios de nobleza para con el paisaje que se desgarra por doquier. El espacio público se halla invadido por las ventas ambulantes y los mercados públicos son un desastre. Las basuras al igual que la cascarilla de arroz inundan la ciudad y sus alrededores.

Otra escritora que hace referencia al crecimiento desordenado de la ciudad en su investigación es Martínez 1992 citado en (Rausch, 2011)

Villavicencio se parecía a cualquier otra ciudad intermedia en Colombia, como Valledupar (Cesar), Ibagué (Tolima), Santa Marta (Magdalena) en cuanto que el acelerado crecimiento demográfico se aunaba con escaso desarrollo industrial, situación que se traduce en marginalidad, urbanización descontrolada y otras distorsiones como el desempleo excesivo y la insuficiencia en la prestación de servicios públicos básicos como agua, electricidad y alcantarillado, para satisfacer las necesidades de la población en expansión. (p. 165).

Llano 7 días 1999 citado (Ojeda, 2000) afirma:

El portal de la Llanura no es un pueblo grande atrasado, es la ciudad más cosmopolita de la Orinoquia, pero pudieran ser muchos más: sí sus gobernantes, legisladores y líderes cívicos: hubiesen tenido visiones y proyecciones de avanzada y no la simple satisfacción de la prebenda clientelistas en la burocracia. Los problemas que vive la ciudad se derivan de la falta de planeación, la carencia de autoridad, la falta de gestión y el nulo compromiso con la urbe y sus moradores y la corrupción administrativa es dominio público y que varios gobernantes en vez de racionalizar el gasto público y de usar adecuadamente los recursos del municipio, se han ido apropiando de él, convirtiéndolos en una cultura corriente, permitiendo que otros lo hagan, sin la menor muestra de vergüenza. (p. 172). 
De acuerdo con lo anterior se puede afirmar que este crecimiento desordenado ha afectado a la ciudad de Villavicencio en todos los aspectos, por lo cual se ha trabajado los últimos 15 años para generar un Plan de Ordenamiento Territorial que responda a las necesidades de la ciudad y que cumpla con la normatividad que exige el gobierno nacional.

Con la constitución política de Colombia ${ }^{3}$ en su artículo 311 el municipio se convierte en la entidad fundamental de la división política administrativa del Estado, propendiendo por el desarrollo del territorio; así el ordenamiento territorial se inserta en un mundo globalizado donde adquiere un sentido de identidad y capacidad de potenciar las oportunidades. Este precepto se reafirma en la Ley Orgánica del Plan de Desarrollo (Ley 152/94) ${ }^{4}$, por la cual los municipios y los planes de desarrollo deben contar con un Plan de Ordenamiento Territorial elaborado con el apoyo técnico del Gobierno Nacional y departamental teniendo como base la Ley 388 de $1997^{5}$ que proporciona las pautas constitucionales y legales para su construcción.

De esta manera surge el Plan de Ordenamiento Territorial como el instrumento básico para desarrollar el proceso de ordenamiento del territorio, constituido por un conjunto de objetivos, directrices, políticas, estrategias, metas, programas, actuaciones y normas adoptadas para orientar el desarrollo físico del territorio y la utilización del suelo (Ley 388/97, art. 9) ${ }^{6}$.

\footnotetext{
${ }^{3}$ Artículo 311. Al municipio como entidad fundamental de la división político-administrativa del Estado le corresponde prestar los servicios públicos que determine la ley, construir las obras que demande el progreso local, ordenar el desarrollo de su territorio, promover la participación comunitaria, el mejoramiento social y cultural de sus habitantes y cumplir las demás funciones que le asignen la Constitución y las leyes.

${ }^{4}$ Ley 152/94, art. 41: Planes de acción en las entidades territoriales. Con base en los planes generales departamentales o municipales aprobados por el correspondiente Concejo o Asamblea, cada secretaría y departamento administrativo preparará, con la coordinación de la oficina de planeación, su correspondiente plan de acción y lo someterá a la aprobación del respectivo Consejo de Gobierno departamental, distrital o municipal. En el caso de los sectores financiados con transferencias nacionales, especialmente educación y salud, estos planes deberán ajustarse a las normas legales establecidas para dichas transferencias. Para el caso de los municipios, además de los planes de desarrollo regulados por la presente Ley, contarán con un plan de ordenamiento que se regirá por las disposiciones especiales sobre la materia.

${ }^{5}$ Ley 388/97, art. 5: define el ordenamiento municipal en los términos de que este "comprende un conjunto de acciones político-administrativas y de planificación física concertados, en ejercicio de la función pública que les compete en orden a disponer de instrumentos eficientes para orientar el desarrollo del territorio bajo su jurisdicción y regular la utilización, transformación y ocupación del espacio, de acuerdo con las estrategias de desarrollo socioeconómico y en armonía con el medio ambiente y las tradiciones históricas y culturales"

${ }^{6}$ Ley 388/97, art. 9: Plan de Ordenamiento Territorial. El plan de ordenamiento territorial que los municipios y distritos deberán adoptar en aplicación de la presente Ley, al cual se refiere el artículo 41 de la Ley 152 de 1994, es el instrumento básico para desarrollar el proceso de ordenamiento del territorio municipal.
} 


\section{METOdOLOGÍA}

Los fenómenos que se presentan con el cambio en el uso y la tenencia del suelo se pueden ver desde una perspectiva global en lo referente a las implicaciones económicas, sociales y políticas, incorporando los impactos negativos que estos fenómenos imponen al medio ambiente del territorio a estudiar; sin embargo, los actores más afectados por estos fenómenos son quienes se encuentran involucrados directamente con el fenómeno y que han tenido que experimentar el proceso de transformación de uso del suelo y las implicaciones que esto ha tenido en su forma de vivir. El incorporar a la investigación un análisis cuantitativo y cualitativo resulta esencial para interpretar estos acontecimientos de una manera más real y profunda.

Para el análisis en el uso y la tenencia de la tierra en las veredas Barcelona, Cocuy y Zuría se utilizaron encuestas y entrevistas a la población de las tres veredas. Las encuestas se aplicaron en los centros poblados de las veredas y viviendas cercanas eligiendo de manera aleatoria a 81 familias entre 400 que habitan allí. Teniendo en cuenta el tamaño de las veredas en relación al número de habitantes se planteó que el $62,5 \%$ de los encuestados fueran de la vereda Barcelona, el 21,2 \% de la vereda Cocuy y el 16,2 \% de la vereda Zuría. Las encuestas se construyeron a partir de dos tipos de preguntas. El primer grupo de preguntas provee datos respecto a las condiciones del hogar y la vivienda e indaga sobre las características económicas y de educación de la población para identificar patrones de comportamiento y tendencias respecto a sus condiciones socioeconómicas; el segundo tipo de preguntas profundiza en el tema de uso y tenencia de la tierra respecto a sus propias experiencias.

Las entrevistas se realizaron a una muestra no aleatoria eligiendo 7 fincas con más de 30 hectáreas de tierra y más de 10 años viviendo allí, de tal manera que pudieran proveer información directa respecto a la transformación en el uso y la tenencia del suelo de estas veredas.

Así las cosas, el desarrollo de la investigación fue de tipo empírico cualitativo, debido que se obtuvieron de manera directa las motivaciones, actitudes y comportamientos de los individuos que estuvieron inmersos en la problemática, lo que permitió determinar de manera precisa la tenencia y uso de la tierra en un sector específico del municipio de Villavicencio, denominado Vereda Suría, para ser analizada en un contexto urbano y que estuvo enfocada en el equilibrio ambiental y el aprovechamiento económico y social. Para este efecto se recolectó, procesó, sistematizó y analizó la información relacionada, además con aspectos 
socioeconómicos que enmarcaron la problemática. Lo cual implicó un trabajo con instrumentos de planimetría para definir las cotas del área de estudio; establecer los mecanismos de medición apropiados así como las formas de valoración y análisis con la finalidad de encontrar algunos indicadores para la validación de los resultados y la inferencia de validez científica.

Igualmente se revisó la literatura reciente sobre tenencia y uso de la tierra, parte de la cual junto con el marco teórico permitieron cotejar algunas evidencias principales, sin embargo se requirió una revisión más precisa sobre todo en lo que tiene que ver con la ley 1625 de 2013 que fija normas específicas para áreas metropolitanas y la 1551 de 2012, que lo hace para modernizar la organización y el funcionamiento de los municipios y finalmente la Ley Orgánica de Ordenamiento Territorial - Ley 1454 de 2011.

El desarrollo de la investigación permitió exponer algunas teorías relacionadas con la tenencia y uso de la tierra, para ser aplicadas en un contexto urbano y enfocadas en el equilibrio ambiental y el aprovechamiento económico.

\section{Unidad de trabajo}

La unidad de trabajo fue en las veredas el Cocuy, Barcelona y Zuría en el municipio de Villavicencio, en cercanía de los predios de la Universidad de los Llanos, cuya área de influencia se muestra en el siguiente mapa.

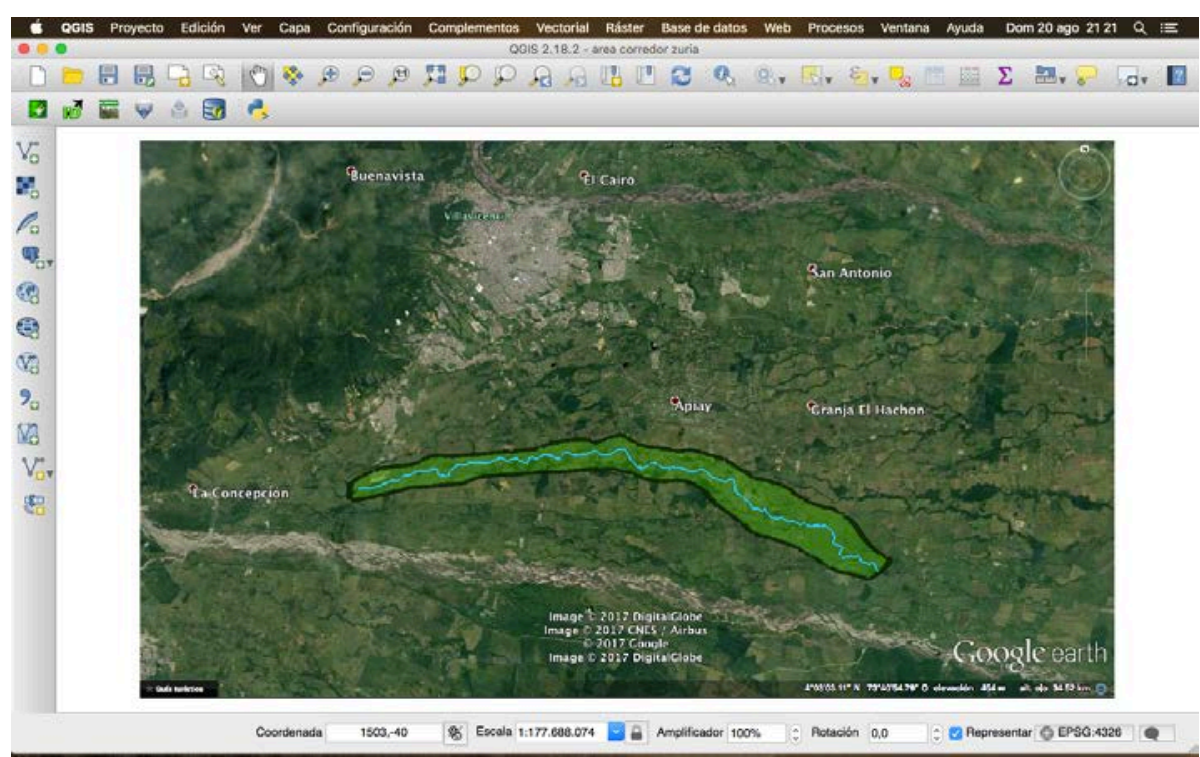

Elaboración propia soportada con Google earth. (c.2014). "Obtenido de US Dept of State Geographer Data SIO, NOAA, U.S. Navy, NGA, GEBCO image LandSat 2014 Google". 


\section{Unidad de análisis}

Para el análisis se tomó como muestra representativa el sector de las veredas Barcelona, El Cocuy y Zuría, con un área de aprox $24 \mathrm{~km}$ lineales y $2 \mathrm{~km}$ al costado del mismo, donde se encuestaron y entrevistaron finqueros, propietarios de predios y a algunos arrendatarios, comprendidos en el sector medio del sector mencionado, que es donde se está presentando el problema de parcelación.

\section{Tipo de investigación}

Se trató de un trabajo empírico deductivo que a partir de información de campo permitió estimar económica y socialmente la aspectos relacionados con la tenencia y uso del suelo en el sector de la vereda Suría en la ciudad de Villavicencio

El método científico sobre el cual se desarrolló la investigación se basó en el tipo inductivo deductivo, ya que de una parte se sacaron conclusiones sobre un caso particular con base en aspectos teóricos relacionados con la teoría del desarrollo sostenible en la parte de aplicación de leyes de tipo ambiental, se pretendió descubrir generalidades relacionadas la tenencia y uso del suelo así como el comportamiento de los actores, a partir de observaciones en campo y apoyadas también en la recolección de información a través de entrevistas en cada una de las unidades productivas (fincas) .

\section{ANÁLISIS CUANTITATIVO}

Los cambios en el uso y la tenencia del suelo rural son determinantes a la hora de identificar si existe o no un desarrollo sostenible del territorio. La ocupación del suelo y su destinación repercuten directamente en la alteración de los recursos naturales al igual que en las condiciones de vida de la población que habita tanto en estas zonas como la ciudad que se beneficia de los recursos ambientales que provee. Una parcelación o subdivisión que genere suburbonización no programada puede generar transformaciones en la vocación del suelo y ocasionar daños tanto al medio ambiente como afectar la calidad de vida de las personas que tienen vivienda o infraestructura allí ya que al estar en zonas no aptas para este tipo de usos no cuentan con acceso a servicios públicos entre otras garantías de vivienda que provee el Estado.

Por tal razón en este apartado se realizó un análisis de los cambios en el uso y tenencia del suelo desde dos puntos de vista, en el primero se analizaron las condiciones socioeconómicas de la población involucrada en la investigación con el objetivo de revisar la 
dinámica social y económica que se ha presentado en los últimos años en las tres veredas, y en la segunda la subdivisión predial de los suelos rurales y sus implicaciones en los cambios en el uso y la tenencia de la tierra.

Este análisis parte de una encuesta aplicada a 79 personas que habitan en las veredas involucradas en la investigación, y que fueron realizadas principalmente en los centros poblados que es donde hay más conglomeración, por tal razón los datos arrojados corresponden en su mayoría a las respuestas dadas por los habitantes de las propiedades más cercanas, siendo en su mayoría propiedades pequeñas.

\section{Análisis socio-económico}

Las veredas Barcelona y Cocuy se encuentran en el corregimiento 7, el segundo corregimiento con mayor población de la ciudad de Villavicencio seguido del corregimiento 1 donde se encuentra la vereda Zuría la cual ocupa tan solo un 0,77 \% del territorio rural de Villavicencio siendo una de las más pequeñas (ver gráfica 1)

\section{Gráfica 1 Distribución de la población en los 7 corregimientos del municipio de Villavicencio, en el año 2011}

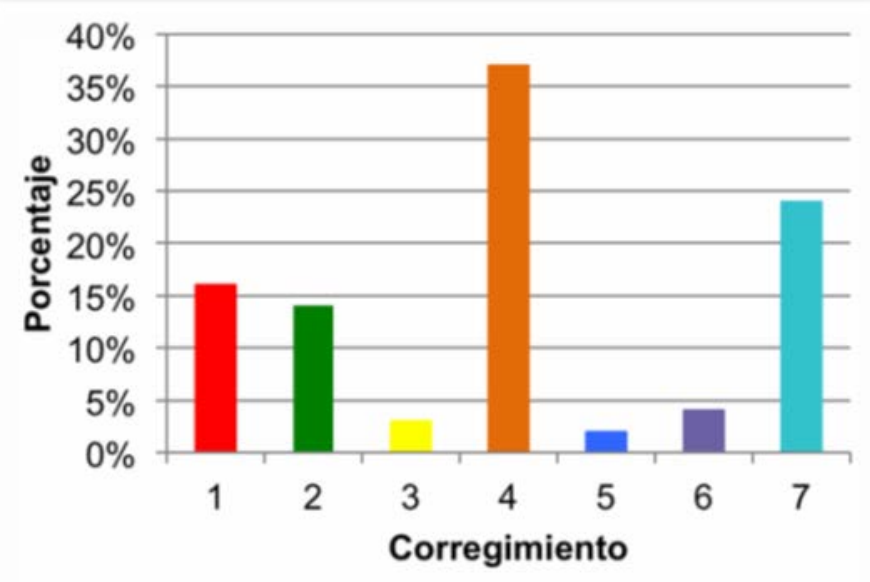

Fuente: Extraído del POT 2015

Tabla 1 Hectáreas por vereda

\begin{tabular}{|c|c|}
\hline $\begin{array}{c}\text { Veredas } \\
\text { Vereda } \\
\text { Barcelona }\end{array}$ & AREA(has) \\
\hline Vereda Cocuy & 3684 \\
\hline Vereda Zuría & 1.159 \\
\hline
\end{tabular}

Fuente: Elaboración propia con datos del POT 2015 
El mayor número de hectáreas de suelo pertenecen a la vereda Barcelona, seguida del Cocuy y Zuría. Las veredas Barcelona y Cocuy cuentan con pequeños centros poblados a diferencia de la vereda Zuría donde solo hay fincas y viviendas campestres.

Estas características son fundamentales a la hora de analizar las condiciones socioeconómicas de los habitantes de estas veredas, ya que las dos primeras al contar con centros poblados tienen una asignación de uso de suelo suburbano que según el POT debe cumplir con unas condiciones básicas que garanticen el acceso a servicios públicos, espacios públicos, infraestructura vial y transporte.

\section{Condiciones Sociales}

El análisis de las condiciones socio-económicas de la población involucrada se realiza teniendo en cuenta variables como el número de integrantes que conforman el grupo familiar, acceso a servicios públicos, nivel de educación e ingresos entre otras variables que son determinantes para analizar la calidad de vida de los habitantes de las veredas.

\section{Estructura familiar}

En las gráficas 3, 4, 5 y 6 se muestra la composición de los grupos familiares que habitan en las veredas.

\section{Gráfica 2. Número de personas que habitan en el hogar}

\section{Número de personas que habitan en el hogar}

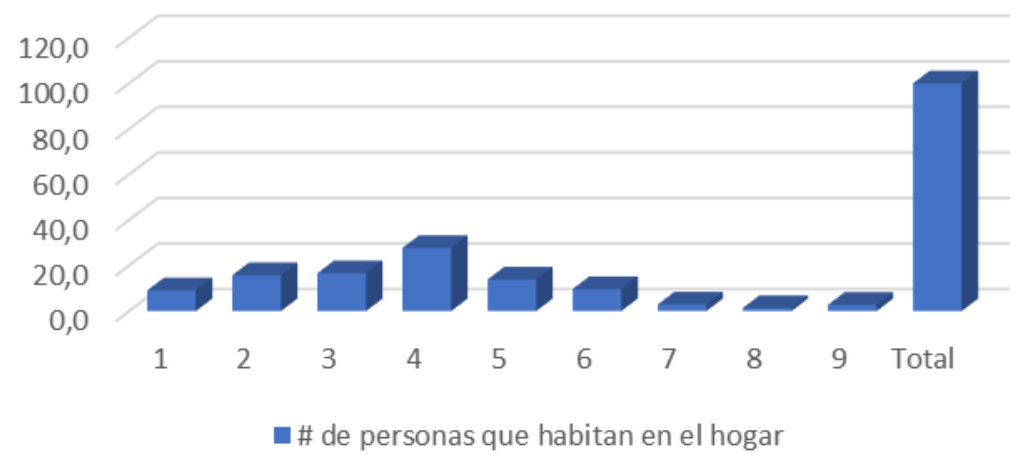

Fuente. Elaboración propia. Formato 1. Encuestas.

Gráfica 3. Número de mujeres que habitan en el hogar 


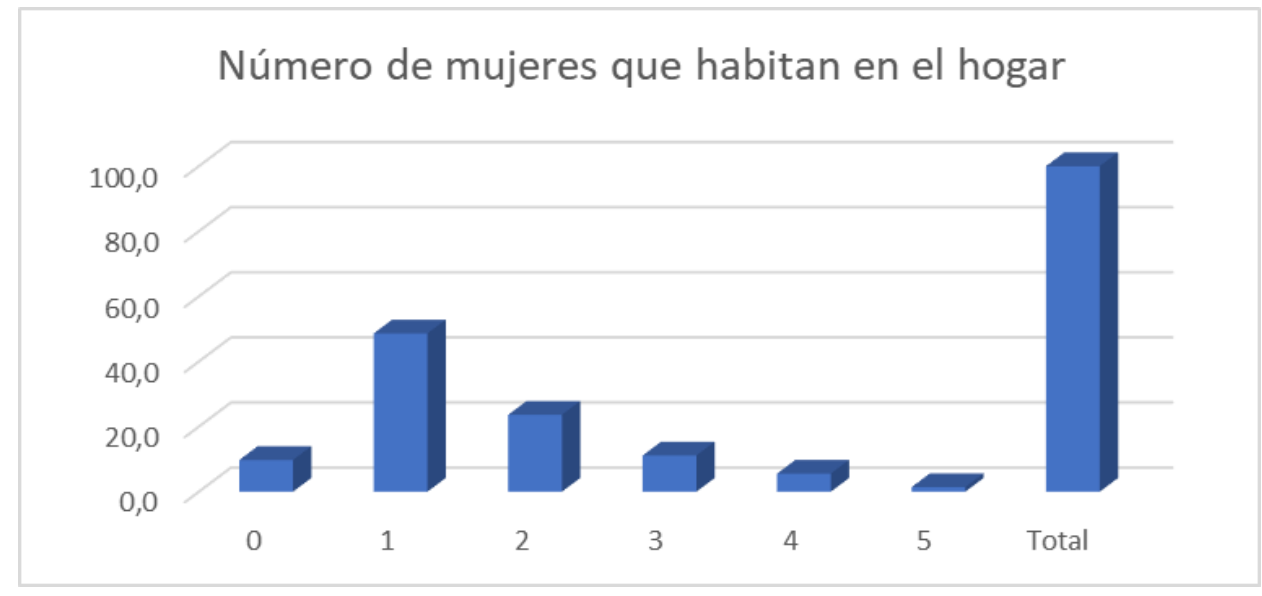

Fuente. Elaboración propia. Formato 1. Encuestas.

Gráfica 4. Número de hombres que habitan en el hogar

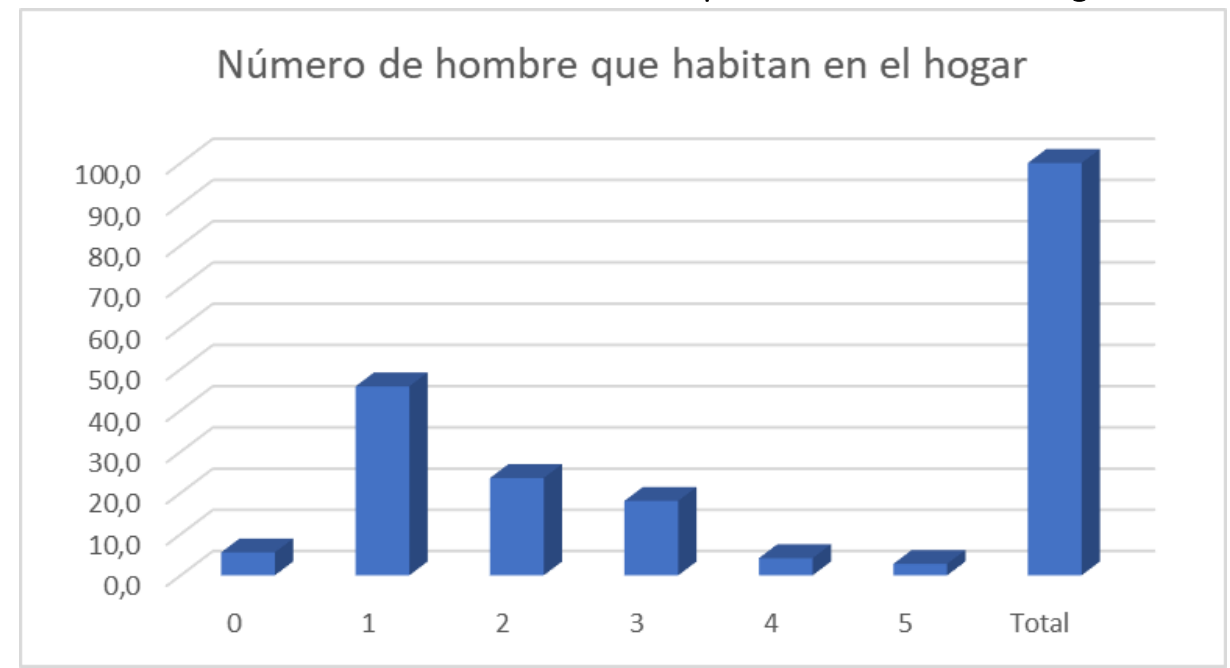

Fuente. Elaboración propia. Formato 1. Encuestas.

Gráfica 5. Número de niños que habitan en el hogar

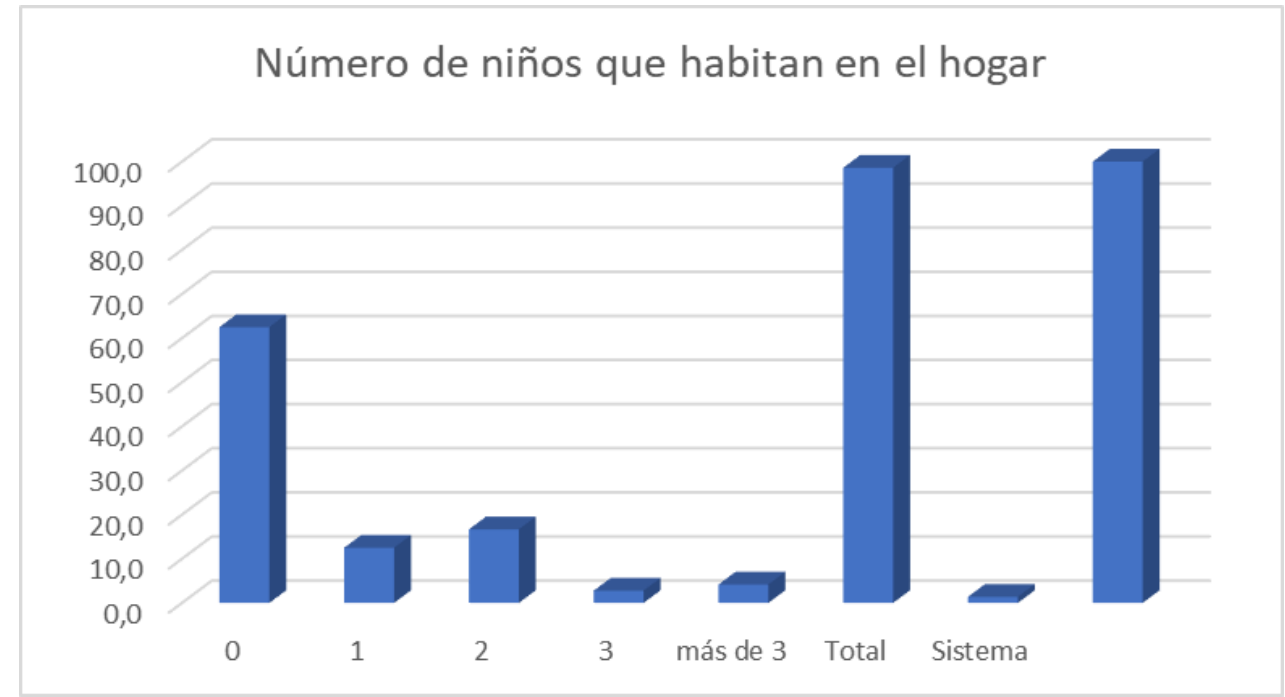

Fuente. Elaboración propia. Formato 1. Encuestas. 
De acuerdo a las gráficas anteriores se puede evidenciar que el grupo familiar más común que constituye cada hogar es de 4 integrantes, una cifra que corresponde más al número de integrantes que posee una familia de la ciudad que una del campo que tradicionalmente suele ser más numerosa. Este tipo de comportamientos se contrastan con la nueva realidad territorial donde se evidencian cambios a nivel social, entre ellos la mezcla de la población rural tradicional con la población que habita en zonas rurales, pero posee características de tipo urbano.

\section{Servicios Públicos}

Gráfica 6 Acceso a servicios públicos
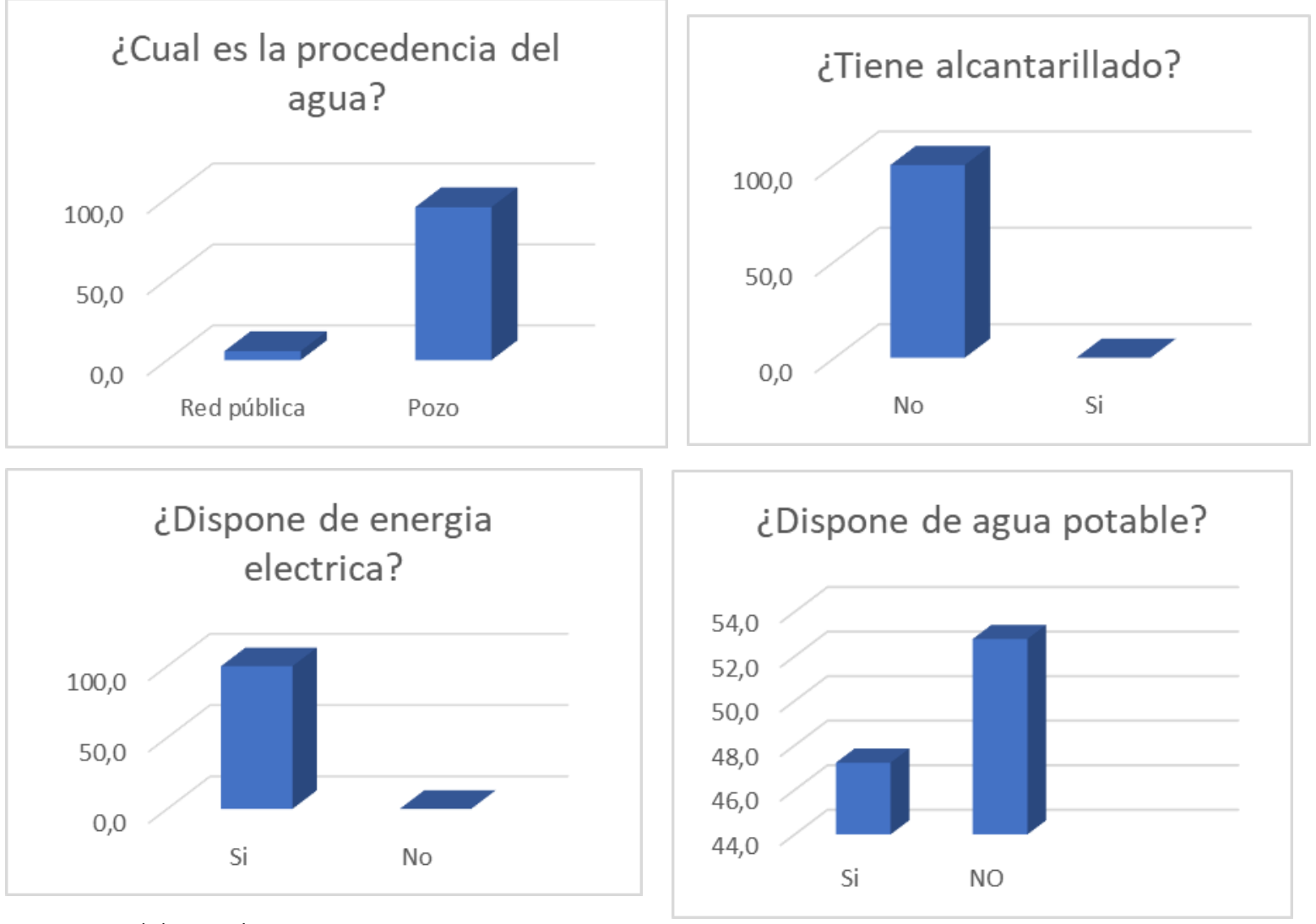

Fuente. Elaboración propia. Formato 1. Encuestas.

De acuerdo a los datos arrojados por las encuestas la población cuenta solo con acceso al servicio de energía eléctrica, el agua no se obtiene a través de red pública sino de un pozo y no existe servicio de alcantarillado. De esta manera se puede evidenciar la falta de asistencia del Estado para sanear los servicios básicos que demanda la población y que es de estricta obligatoriedad por el carácter de Centros Poblados que existen en dos de las veredas. 


\section{Educación}

Tabla 2 Nivel de Educación de la población de las veredas Barcelona, Cocuy y Zuría

\begin{tabular}{|c|c|c|c|c|c|c|c|c|}
\hline & \multicolumn{6}{|c|}{ ¿Cuánto hace que vive acá (años)? } & \multirow[b]{2}{*}{ Total } \\
\hline & & $\begin{array}{c}\text { entre } \\
0-2 \\
\text { años }\end{array}$ & $\begin{array}{c}\text { entre } \\
2-4 \\
\text { años }\end{array}$ & $\begin{array}{l}\text { entre } \\
4-6 \\
\text { años }\end{array}$ & $\begin{array}{l}\text { entre } \\
6-8 \\
\text { años }\end{array}$ & $\begin{array}{l}\text { entre } \\
\text { 8-10 } \\
\text { años }\end{array}$ & $\begin{array}{l}\text { mas } \\
\text { de } 10 \\
\text { años }\end{array}$ & \\
\hline \multirow{4}{*}{$\begin{array}{c}\text { Nivel de } \\
\text { educación del } \\
\text { encuestado }\end{array}$} & Primaria & $4 \%$ & $6 \%$ & $1 \%$ & $1 \%$ & $0 \%$ & $20 \%$ & $33 \%$ \\
\hline & Secundaria & $6 \%$ & $6 \%$ & $3 \%$ & $0 \%$ & $4 \%$ & $14 \%$ & $33 \%$ \\
\hline & Técnica & $3 \%$ & $1 \%$ & $3 \%$ & $0 \%$ & $3 \%$ & $6 \%$ & $16 \%$ \\
\hline & Superior & $9 \%$ & $1 \%$ & $0 \%$ & $0 \%$ & $0 \%$ & $9 \%$ & $19 \%$ \\
\hline \multicolumn{2}{|c|}{ Total } & $21 \%$ & $14 \%$ & $7 \%$ & $1 \%$ & $7 \%$ & $49 \%$ & $100 \%$ \\
\hline
\end{tabular}

Fuente. Elaboración propia. Formato 1. Encuestas.

De acuerdo a los datos arrojados por las encuestas el 66\% de la población se encuentra en los rangos de básica primaria y secundaria. Al contrastar estos datos con el tiempo que llevan viviendo en la vereda se evidencia que el mayor porcentaje de encuestados que no sobrepasan el bachillerato son personas que llevan más de diez años en la vereda. Este hecho se puede explicar por la falta de acceso a la educación hace algunos años ya que estas veredas no contaban con vías de transportes y la movilidad era más limitada dificultando el desplazamiento hacia las pocas instituciones educativas existentes.

\section{Condiciones Económicas}

Gráfica 7 Ingresos mensuales familias Veredas Barcelona, Cocuy y Zuría

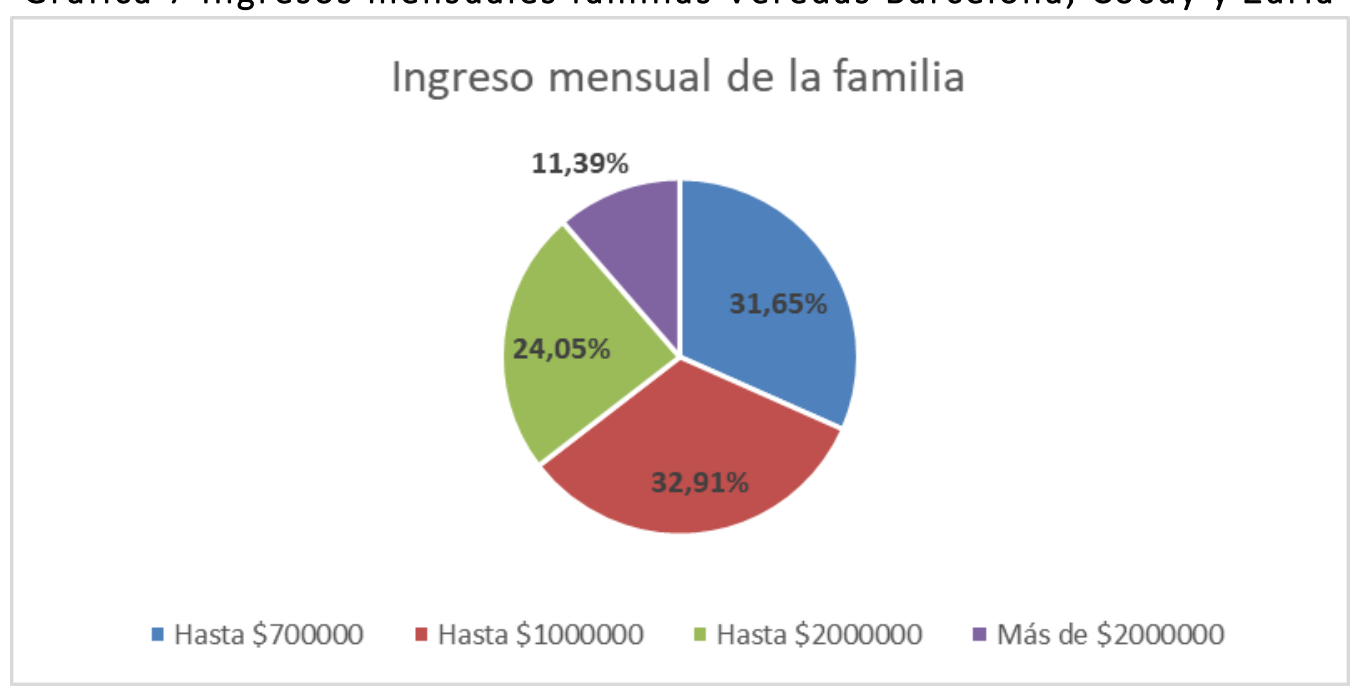

Fuente: Elaboración propia. Formato 1. Entrevistas grupo de Investigación TRADO. 
En la gráfica 9 se evidencia que el $64,6 \%$ de las familias de las tres veredas tienen ingresos mensuales menores de $\$ 1.000 .000$, un 24,05\% cuentan con ingresos de hasta $\$ 2.000 .000$ y un $11,39 \%$ con más de $\$ 2.000 .000$ mensuales. De acuerdo a estos datos la brecha en las condiciones económicas de la población es indiscutible. Gran parte de los habitantes poseen poca capacidad adquisitiva lo cual se puede atribuir a los bajos niveles de educación que repercuten en trabajos no calificados con salarios bajos, mientras que una pequeña parte suele tener rentas más elevadas. A la luz de la nueva realidad territorial esto se puede explicar por la transformación en el uso y la tenencia del suelo rural que se encuentra cercano a la periferia urbana, donde los modos de vida y cultura típicos de los espacios rurales son usurpados por grupos de personas con rentas altas que buscan lugares lejos de la congestión de la ciudad, pero cerca a los servicios que esta provee. Como lo expone Ferrero:

Se generan grupos socio-económicos dentro de las veredas donde los nativos suelen estar en zonas más céntricas y las urbanizaciones donde se concentran los nuevos residentes con rentas altas, se encuentran alejadas de cualquier tipo de establecimiento, lo que se traduce en un aislamiento entre los diversos grupos socio-económicos (Ferrero, 2010, p. 56).

\section{Gráfica 8 Actividad económica de las familias en las veredas Barcelona, Cocuy y Zuría}

\section{¿Cuál es la actividad económica de la familia?}

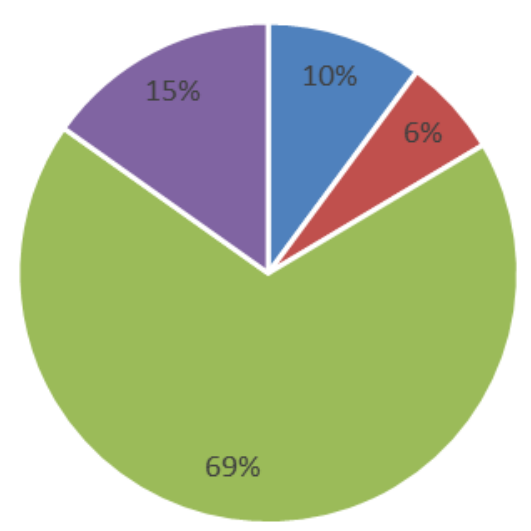

- Ganadera

- Agrícola

- Sector Privado

- Sctor Público

Fuente: Elaboración propia, Formato 1. Entrevistas grupo de Investigación TRADO.

La gráfica refleja que el $69 \%$ de las personas laboralmente activas que habitan en las tres veredas se dedica a trabajar en el sector privado (entre estos principalmente están personas que laboran en Villavicencio o tienen un lugar de comercio dentro de las veredas), el 15\% en el sector público, un $10 \%$ se dedica a la ganadería y tan solo un $6 \%$ a labores agrícolas, 
lo anterior refleja que la vocación económica ha venido cambiando, siendo el uso del suelo un determinante en las condiciones laborales de sus habitantes. Usualmente el suelo rural se destina a actividades como la agricultura y la ganadería y la población que habita allí se sustenta en base a estas actividades, sin embargo, la proximidad de la zona urbana y la buena accesibilidad de las zonas rurales suburbanas a la ciudad ha generado un proceso de transformación en el comportamiento socio-económico de la población de estas veredas. Este comportamiento contrasta con lo dicho en el marco teórico donde se expone el nuevo concepto de ciudad-campo donde los límites entre uno y otro son cada vez más difíciles de detectar y las actividades propias de cada territorio dejan de ser exclusivas de cada uno.

\section{Uso y tenencia de la tierra}

El tamaño de los predios es fundamental para determinar el uso del suelo rural, ya que dependiendo de su extensión se puede estimar la cantidad de hectáreas destinadas a reserva forestal y al uso de actividades productivas. La tendencia a la subdivisión de predios permite identificar los impactos ya sean negativos o positivos sobre el suelo y los recursos naturales. Por tal motivo en este apartado se realiza un análisis de acuerdo a los datos arrojados por las encuestas y se hace un contraste con el uso y la tenencia del suelo en las demás zonas rurales del municipio de Villavicencio.

\section{Subdivisión predial de los suelos rurales en las veredas Barcelona, Cocuy y Zuría}

Gráfica 9. Tamaño de predios en las veredas Barcelona, Cocuy y Zuría.

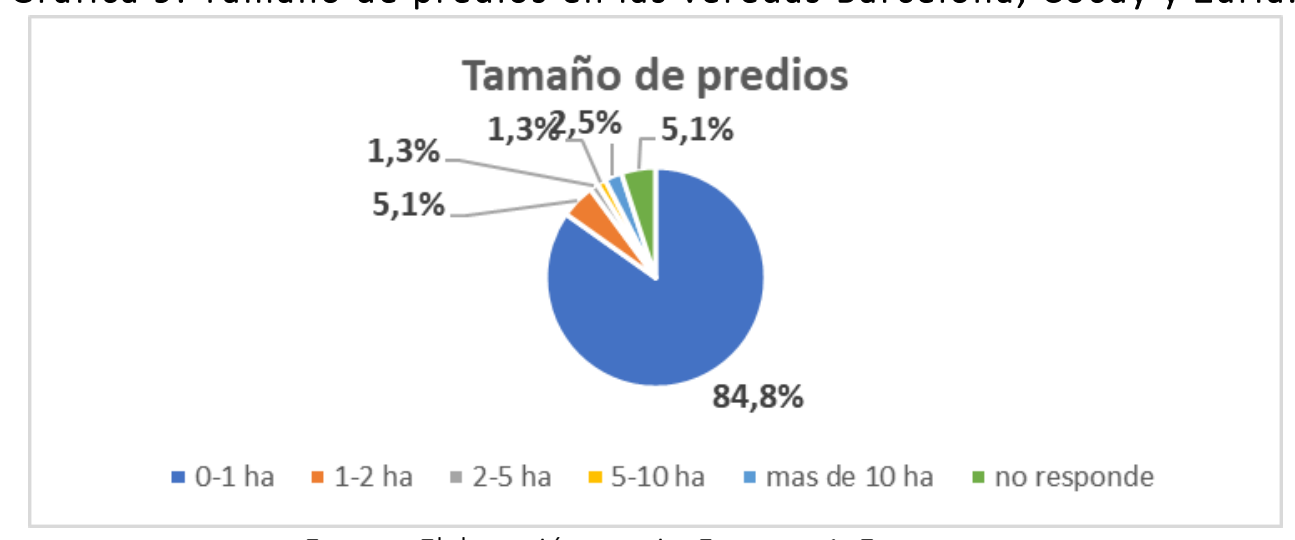

Fuente: Elaboración propia. Formato 1. Encuestas.

En la Gráfica anterior se puede apreciar que el $84,8 \%$ de los predios se encuentran en el rango de 0 a 1 Has, lo que es un dato preocupante en una zona donde el fraccionamiento de los predios está muy por debajo de lo permitido en la normatividad contemplada en el POT para 
suelos rurales, los cuales deben poseer cerca de 34 Has que representan la UAF (Unidad Agrícola Familiar) para garantizar el desarrollo de actividades propias del campo como la agricultura, ganadería y garantizar la conservación de fuentes hídricas y bosques naturales que proveen los servicios ambientales al territorio

Aún teniendo en cuenta que existen centros poblados dentro de las veredas, el que el solo $2,5 \%$ de la población posea más de 10 hectáreas desencadena una serie de implicaciones negativas de carácter medio ambiental, así como desaprovechamiento de tierras productivas, como lo muestra la gráfica 17 en donde el 90\% de la población dedica entre 0-1 hectáreas para realizar labores de cultivo, el cual es más de tipo de autoconsumo y no representa una fuente de ingresos.

Gráfica 10. Área productiva del predio.

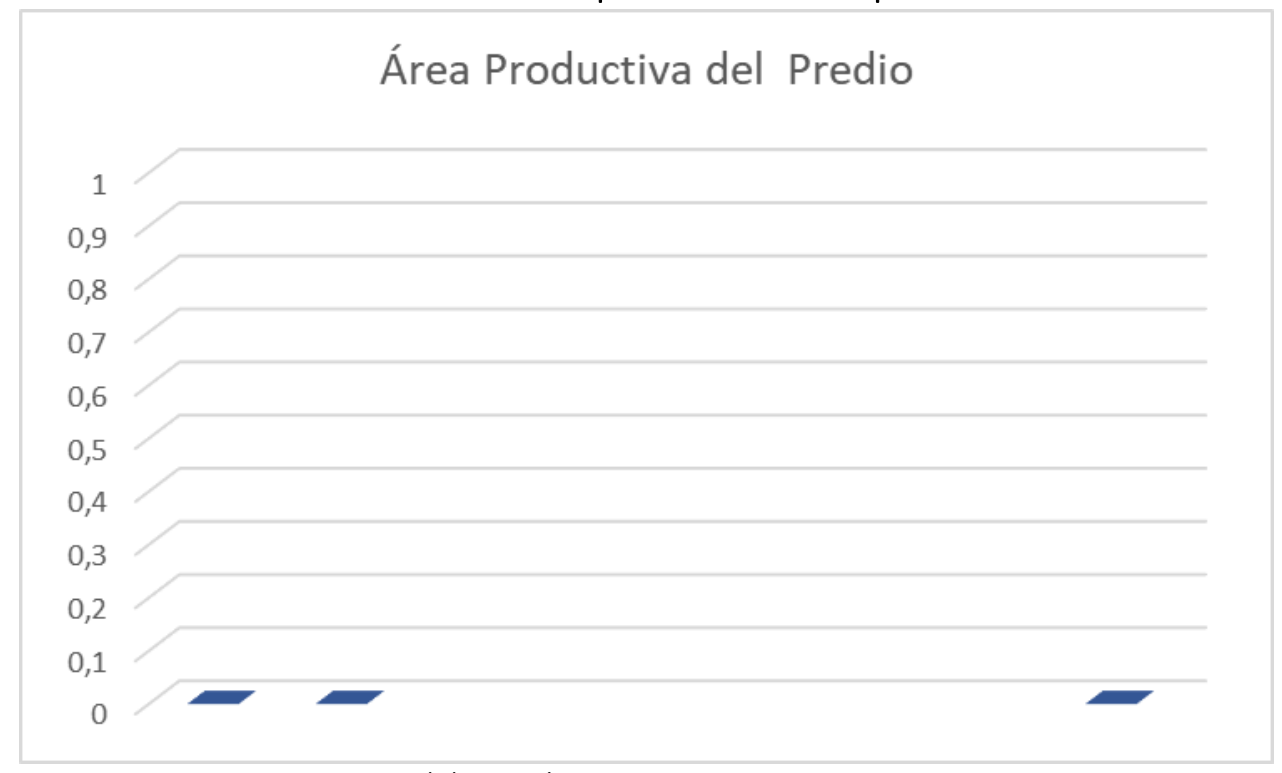

Fuente. Elaboración propia. Formato 1. Encuestas.

Subdivisión predial en las veredas de la ciudad de Villavicencio 


\section{Gráfica 11. Tamaño (has) de los predios rurales de la población muestreada}

\section{TAMAÑO DE LOS PREDIOS RURALES}

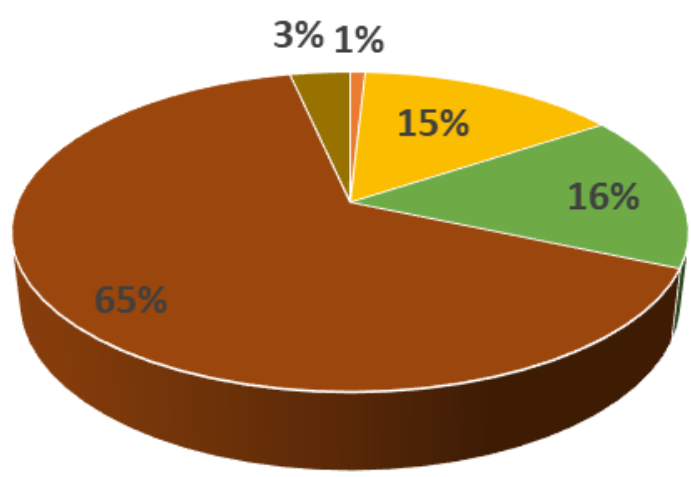

- Sin tierra " Mas de 10 Has de 5 a 9,99 Has - de 0,001 a 4,99 Has " No responde

Fuente: Extraído del POT 2015 Villavicencio.

Los suelos rurales de Villavicencio presentan una tendencia similar a la de las veredas implicadas en la investigación, el 65\% de los predios se encuentran entre 0,01 y 4,99 has, el $15,8 \%$ de 5 a 9,99 has y $14,8 \%$ cuenta con predios mayores a 10 has. De acuerdo al análisis planteado por el equipo del POT (Secretaria de Planeación Municipal, Villavicencio, 2015) se presenta una tendencia de crecimiento en el número de predios con rango de 0 a 3 has, lo que se evidencia en el aumento de predios y la disminución del tamaño predial (73\% del número total de predios en centros poblados están en rango de 0 a $400 \mathrm{~m}^{2}$ ). (Ver gráfica 15)

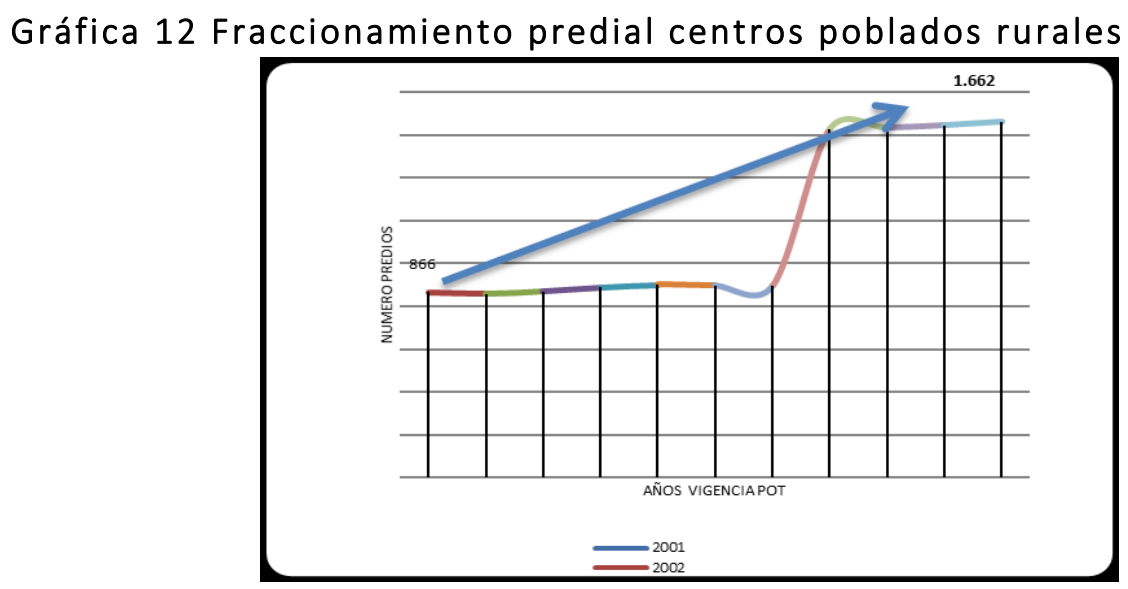

Fuente: Plan de Ordenamiento Territorial 2015.

De acuerdo al comportamiento que presentan las veredas Barcelona, Cocuy y Zuría con respecto al resto de la zona rural de la ciudad en el fraccionamiento predial, se puede concluir 
que existe un acelerado crecimiento de las zonas suburbanas sin planificación por parte de las entidades de control. Como lo menciona Ferrero (2010):

La planificación territorial parece haber dirigido con éxito la construcción hacia zonas prefijadas, pero ha sido incapaz de impedir la expansión hacia afuera de los desarrollos urbanísticos de baja densidad de manera casi ilimitada. Por lo que se puede afirmar que la planificación ha sido poco efectiva en términos de control de cantidad de suelo consumido, bien porque los objetivos no han sido explícitos, bien porque no han sido suficientemente restrictivos o simplemente porque no se han cumplido (p. 22).

Los suelos rurales representan la principal fuente de recursos medio-ambientales y el abastecimiento de materias, para proveer estos servicios requiere de grandes extensiones de tierras dedicadas a reservas naturales y desarrollo de actividades agrarias y pecuarias, sin embargo la alta tendencia a la subdivisión se está convirtiendo en una amenaza para la sostenibilidad ambiental y el desarrollo sostenible no solo de las veredas sino también la ciudad que se ve beneficiada por los recursos naturales del campo y las materias primas extraídas de allí, y en esta situación el municipio carga con gran parte de la responsabilidad por ser el gestor del desarrollo y la planificación territorial.

\section{ANÁLISIS DEL USO Y LA TENENCIA DE LA TIERRA DESDE LA PERSPECTIVA DE LOS ACTORES}

Para soportar la investigación y hacer un estudio cercano a la realidad se realizó un análisis desde la perspectiva de los actores implicados.

Para hacer este análisis se realizaron entrevistas a siete actores elegidos de las tres veredas, el formato para las entrevistas fue de tipo semiestructurado con preguntas abiertas, (Ver anexo 1).

\section{Caracterización de la Población y Descripción del Contexto}

Las preguntas centrales de este estudio surgieron del conocimiento previo de acuerdo a los resultados de las encuestas. Al inicio se interesó conocer las características de los actores, como y porque llegaron al territorio, que factores incidieron en su permanencia en el sector.

Posteriormente en identificar como ha sido el uso y tenencia de la tierra en las tres veredas en los últimos diez años, qué opinión tiene respecto al aumento en el valor de tierra, cual fue y cual es ahora la principal actividad económica de las veredas, que actividad agropecuaria ha realizado o realiza en la finca, si cuenta con bosques de conservación, y manejo ambiental del suelo. 
Finalmente en evaluar el conocimiento de los actores en los planes de ordenamiento territorial y participación en la elaboración o socialización de estos.

De acuerdo a lo anterior las preguntas se dividieron en tres categorías, como se evidencia en el siguiente cuadro:

\begin{tabular}{|c|c|}
\hline Categoría 1 - Descriptiva & $\begin{array}{c}\text { Caracterización de la población y descripción del } \\
\text { contexto }\end{array}$ \\
\hline Categoría 2 - Uso del suelo & Uso y tenencia del suelo en los últimos diez años \\
\hline $\begin{array}{c}\text { Categoría 3 - Planes de ordenamiento } \\
\text { Territorial }\end{array}$ & $\begin{array}{c}\text { Conocimiento y aplicación de los planes de } \\
\text { ordenamiento territorial }\end{array}$ \\
\hline
\end{tabular}

Para elegir a los actores que participaron en la entrevista se tuvieron en cuenta los siguientes parámetros:

1. Los participantes debían tener más de diez años viviendo en la vereda

2. Los participantes debían tener predios con mínimo 30 hectáreas.

3. Las fincas debían realizar algún tipo de actividad productiva agropecuaria.

Inicialmente se intentó realizar la entrevista a los propietarios, pero algunos no se encontraban en la ciudad y otros habían arrendado el predio, por tal motivo 3 de los entrevistados fueron propietarios de los predios, 3 encargados y un arrendatario.

La totalidad de los actores manifestaron que han crecido en el contexto rural, los encargados generalmente han sido cuidadores en su etapa laboral y los propietarios aseguran que heredaron de sus padres la actividad económica a la que se dedican, por lo tanto llegaron a la vereda desde niños debido a que sus padres tenían estos predios para desarrollar actividades económicas de agricultura y ganadería; por otra parte el señor Gustavo García que es el arrendatario, afirma que se dedica al trabajo en la zona rural desde hace siete años, luego de retirarse de trabajar en empresas privadas y decidió emprender un nuevo proyecto (cultivo de piña) que le produjera excedentes y la posibilidad de generar empleos, afirma que la razón principal de permanecer en la vereda es la cercanía con la ciudad de Villavicencio que le brinda como ventajas facilidad distribuir su producto, menores costos y tiempo de transporte, adicionalmente la facilidad para estar pendiente del cultivo.

El nivel educativo, los propietarios de la tierra tienen estudios de pregrado al igual que el arrendatario; los encargados tenían como patrón común que contaban con estudios básicos de primaria y bachiller.

Las condiciones económicas de los participantes están ligadas a la tenencia de la tierra, mientras los cuidadores o encargados cuentan con un salario básico por la labor realizada, el 
arrendatario y los propietarios trabajan de manera independiente. Los propietarios de la tierra para este caso cuentan con mayores ingresos porque explotan la tierra para desarrollar una actividad económica sin pagar el valor de la renta de la tierra, el arrendatario cuenta con los ingresos generados por el cultivo de piña que maneja en esta tierra.

De acuerdo a lo anterior un factor común por el cual los actores permanecen en estas veredas es por la cercanía con la ciudad de Villavicencio, aproximadamente desde el centro de la ciudad hasta las veredas el tiempo aproximado del recorrido es de 25 a 30 minutos con trafico normal, cuentan con dos entradas por diferentes puntos de la ciudad, aunque la entrada por el barrio Juan Pablo no está pavimentada también la usan, los habitantes de la vereda Zuría la transitan con más frecuencia, otra ventaja es la tranquilidad, el aire, una mejor calidad de vida que se tiene en la zona rural pero muy cerca a los beneficios que tiene la zona urbana, tales como centros médicos, educación, lugares de diversión, entre otros.

\section{Uso y tenencia del suelo en las veredas Barcelona, Zuría y Cocuy en los últimos diez años}

\section{Valorización del suelo en los últimos diez años}

Los actores que poseen tierras aseguran que no estarían dispuestos a vender su tierra completamente debido a que es un buen lugar para vivir teniendo la tranquilidad de una zona rural pero muy cerca de la ciudad, por lo que cuentan con todos los servicios necesarios para tener una buena calidad de vida. Tienen conocimiento que las veredas Barcelona, Cocuy y Zuría son suelos en transición de lo rural a lo urbano por lo que sus tierras cada vez se valorizan más.

El valor que tenían sus tierras hace diez años se ha incrementado de forma acelerada, para el 2001 la hectárea se costaba aproximadamente $\$ 21.000 .000$, actualmente se ofrecen entre 300 a 400 millones dependiendo del lugar, si está sobre la avenida principal el valor es más alto. En su mayoría los actores afirman que el valor de la tierra no es adecuado porque está ligado a la especulación en los precios principalmente por la cercanía con la capital del Meta, aunque una minoría afirma que este valor es el correcto y que cada día aumentara más. Desde su perspectiva consideran que la valorización significativa que se ha presentado en los 10 últimos años en esta zona se debe principalmente al crecimiento de la ciudad de Villavicencio que se está quedando pequeña por lo que las tierras rurales más cercanas pueden convertirse en una extensión urbana de la ciudad.

Según un informe del Instituto Geográfico Agustín Codazzi en marzo de 2015, Villavicencio es la ciudad más valorizada del departamento del Meta con un costo de 
\$9.735.443.777.200 (\$9,7 billones de pesos). Está conformada por 172.282 predios urbanos y rurales, con una extensión de 1.247.160.223 metros cuadrados (mil 247 millones 160 mil 2213) y 15.668.312 metros cuadrados de área construida (un poco más de 15 millones de metros cuadrados). (Tovar, 2015).

\section{Uso de la tierra}

Los actores afirman que hace unos veinte años la mayoría de fincas poseían una extensión de más de 200 hectáreas donde trabajaban la ganadería y que actualmente no existen más de 20 fincas que cuenten con más de 30 hectáreas, por otro lado el uso del suelo hace diez años se encontraba fuertemente ligado a la actividad ganadera con presencia no muy significativa de la agricultura. De acuerdo a los actores las veredas hacen parte de lo que alguna vez fue un camino ganadero que transportaba ganado de la zona rural a la capital del Meta, por lo que se convirtió en tierras tradicionalmente ganaderas. Actualmente la ganadería continúa siendo la principal actividad, aunque cada vez tiene menos relevancia dentro de las actividades económicas del sector.

La agricultura se ha convertido en una actividad casi inexistente a excepción de unos cuantos cultivos de piña, melón, sandía entre otros que no requieren suelos muy fértiles. Los actores sostienen que en los suelos de las tres veredas se pueden desarrollar actividades agrícolas tales como agricultura de cultivos específicos de acuerdo al clima y el suelo, cultivo de piña, melón, sandía, papaya, arroz, sin embargo manifiestan que apostarle a la agricultura es más arriesgado que la ganadería y requiere más costos en mano de obra, por lo cual las pocas plantaciones que tienen son para el autoconsumo; con excepción del arrendatario que cuenta con un cultivo de piña como su actividad económica principal.

Una actividad que cada vez está tomando más fuerza en el sector en los últimos cinco años ha sido el turismo, las fincas turísticas se ha convertido en un negocio rentable que requiere menos inversión de dinero y tierra. Afirman que el crecimiento de este sector ha sido acelerado, cada día se ven más fincas que prestan servicios de recreación y hospedaje destinados al turismo o momentos de descanso.

Los actores son conscientes de que estas tierras están teniendo un crecimiento urbano acelerado, que se ha visto reflejado en la parcelación de tierras por áreas cada vez más pequeñas. Pese a la normatividad que exige un mínimo de hectáreas para parcelar en la práctica se evidencia cada vez más un aumento de construcciones residenciales escudadas en excepciones y singularidades de la ley. 
El Departamento del Meta en sus últimos planes de desarrollo ha realizado una apuesta importante al sector turístico, ya que considera que puede dinamizar la economía departamental significativamente, como lo plantea el Banco de la Republica en un ensayo sobre economía regional.

El desarrollo del sector turismo resulta de trascendental importancia para la economía del departamento, si se tienen en cuenta algunos elementos estructurales de la actividad y los desarrollos coyunturales en materia de desarrollo en infraestructura vial y hotelera fundamentalmente. Sobre la importancia del sector basta resaltar su dinámico papel como agente multiplicador de otras actividades económicas complementarias. Los desarrollos viales, en los que se destaca la construcción y modernización de la carretera Villavicencio - Bogotá, así como el crecimiento de condominios habitacionales y turísticos en las áreas rurales del departamento por parte de inversionistas privados y de algunas Cajas de Compensación Familiar de Bogotá, y la constitución y adaptación de fincas para el desarrollo del agroturismo y ecoturismo, proyectan al departamento del Meta como un destino turístico apetecido por sus factores de novedad, cercanía y clima, entre otros. (Bottía, 2004)

\section{Manejo medioambiental del suelo}

La ganadería empleada en estas tierras es de tipo extensiva, por lo que requiere de grandes superficies de tierras con pastos para alimentar al ganado, de acuerdo a los actores que trabajan en esta actividad el suelo utilizados han sido los mismos desde que compraron los terrenos por lo que nunca han requerido de la tala de bosques; al ser tradicionalmente tierras ganaderas ya contaban con espacios para trabajar el ganado. En cuanto el tema de abonos, control de maleza y fertilizantes, la mayoría de los actores afirman que tratan en lo posible no utilizar abonos químicos ni fertilizantes, las malezas son usualmente arrancadas sin necesidad de venenos o con guadaña, adicionalmente la mayoría de los actores afirman que los suelos no requieren de fuertes productos químicos ya que no necesitan que sean fértiles. A excepción del señor Gustavo García que por el cultivo de piña necesariamente hace uso de químicos para proveer los nutrientes que el suelo necesita, él asegura que un cultivo orgánico requiere de un elevado costo que los consumidores no estarían dispuestos a asumir.

Según los actores ellos cuentan con bosques de reserva en su finca de acuerdo a lo que exige la norma ambiental, no realizan ninguna actividad puntual para protegerlos, simplemente no extraen madera ni animales del bosque, adicionalmente afirman que algunas entidades universitarias realizaron una campaña para sembrar árboles para conservar las laderas de los ríos, pero solo realizaron solo una visita y no han regresado. 
De acuerdo a lo anterior, hace falta acompañamiento por parte de las autoridades competentes, que para este caso sería CORMACARENA. También por instituciones que generen conciencia de la importancia y obligación que tienen en el tema de conservación ambiental en las veredas. Se evidencia en la mayoría de actores desconocimiento y confusión en cuanto a las normas ambientales. Adicionalmente afirman que cuando CORMACARENA llega al sector simplemente lo hace para imponer sanciones, pero no realizan ningún tipo de apoyo o capacitaciones.

\section{Conocimiento y aplicación de los Planes de Ordenamiento Territorial}

El ordenamiento territorial debe ser un instrumento que permita direccionar las inversiones de los gobiernos locales y nacionales e impulsar las inversiones privadas con el fin de mejorar la calidad de vida de la población, debe proveer una visión transversal e integral de los problemas y lo que se pretende para un determinado territorio.

En este proceso de construcción de ordenamiento territorial la participación ciudadana es fundamental, ya que permite tener una mirada cercana a las necesidades de las comunidades ubicadas en dicho territorio. De acuerdo a lo anterior se preguntó a los actores si tenían conocimiento sobre el actual plan de Ordenamiento territorial (2015) del municipio de Villavicencio, la mayoría afirmó no tener conocimiento del contenido de los planes, ni de los conceptos referentes al uso del suelo rural. En su totalidad sus respuestas fueron contradictorias cuando se les preguntó si sabían a qué tipo de suelo pertenecían sus tierras, algunos las consideraban tierras en expansión urbana por la cercanía a la ciudad para otros eran suelos rurales que aún no estaban preparados para la urbanización, sin embargo, ninguno vinculó el tipo de suelo con la normatividad existente en planeación territorial.

La desinformación de los actores, se asocia al hecho de que ninguno de ellos asistió a las reuniones convocadas por planeación municipal para participar en la construcción del POT, la mayoría afirmó no haber sido invitado a ninguna reunión mientras que otros reconocieron que se hizo la convocatoria pero que no asistieron por falta de tiempo.

De acuerdo a la memoria justificativa del POT el proceso de formulación del plan de ordenamiento territorial para Villavicencio se caracterizó por una amplia convocatoria y participación de la comunidad de la zona urbana y rural, afirman que en la fase pedagógica participaron 1.116 personas, la etapa de diagnóstico contó con la participación de 1.044 personas en donde se realizaron mesas de trabajo se trabajaron temáticas de sostenibilidad ambiental, modelos de ocupación y uso del suelo, espacio público y aprovechamiento del suelo, 
infraestructura, movilidad, vivienda y servicios públicos y finalmente la etapa formulación con la participación de 1.184 asistentes.

Pese a que se realizó la convocatoria la mayoría de los actores no se dio por enterado o no tuvo interés de asistir por lo que se evidenció el amplio desconocimiento de la normatividad.

\section{CONCLUSIONES}

Las tendencias de desarrollo territorial están llevando a una creciente penetración del suelo urbano al suelo rural en la ciudad de Villavicencio que se ven reflejadas en la construcción de viviendas y fincas turísticas con espacios reducidos que no cumplen con la normatividad estipulada para suelo rural y están ocasionando transformaciones en la vocación productiva, así como deterioro ambiental por la reducción de bosques y fuentes hídricas.

Los mecanismos de planificación territorial no han sido eficaces a la hora de controlar las dinámicas de urbanización del suelo rural, por lo que los centros poblados se han expandido sin ningún control y planificación.

Frente al crecimiento poblacional que es inevitable en una ciudad intermedia como Villavicencio, la discusión sobre el uso del suelo se debe centrar en controlar los procesos de urbanización y expansión urbana y dirigir la atención hacia los terrenos ya existentes para planificar adecuadamente el aprovechamiento del suelo y generar una urbanización compacta y sostenible.

\section{REFERENCIAS BIBLIOGRÁFICAS}

AGUILAR, A. (1999). La ciudad de México en la región centro. Nuevas formas de la expansion metropolitana. Mexico: Plaza y valdés editores. (2006). La ciudad de México y su estructura policentrica regional. Mexico: IG-UNAM, CONACYT Miguel Ángel Porrúa editores.

ARIAS, P. (2005). Nueva Ruralidad: Antropólogos y geógrafos frente al campo hoy. Recuperado de http://fenix.cichcu.unam.mx/libroe_2006/0004175/07_03.pdf.

BANCO INTERAMERICANO DE DESARROLLO BID. (2011). Sostenibilidad urbana en América Latina y el Caribe. Banco Interamericano de Desarrollo. Oficina de Relaciones Externas del BID. Recuperado en 2017, de https://courses.edx.org/courses/IDBX/IDB_LSC101x/3T2014/pdfbook/0/.

BARQNA, G., GOMEZ, A., \& DOMINGUEZ, C. (s.f.). El proceso de construcción territorial de la orinoquia colombiana en el siglo XIX. Recuperado de http://www.bdigital.unal.edu.co/7352/1/EL_PROCESO_DE_CONSTRUCCI\%C3\%93N_TERRITORIA L_DE_LA_ORINOQUIA_COLOMBIANA_EN_EL_SIGLO_XIX.p df. 
BARQUERO, A. V. (2000). Desarrollo económico local y descentralización: aproximación a un marco conceptual. Santiago, Chile.CEPAL división de desarrollo económico.

BORJA, M. (1996). Estado, sociedad y ordenamiento territorial en Colombia . Bogotá: CEREC.

BOTTíA, H. G. (Septiembre de 2004). Banco de la República. Recuperado de El turismo como alternativa de desarrollo para Villavicencio y el departamento del meta:

http://www.banrep.gov.co/docum/Lectura_finanzas/pdf/2004_septiembre.pdf.

CALVET PUIT, M. (2005). Incidencia de l'urbanisme en la funció economica i social de la ciutat: el rol de les ciutats mitijanes en un entorn metropolita. Catalunya: Tesis doctoral de la universitat Politecnica de Catalunya UPC.

CARAGGIO, J. (1999). Condiciones de posibilidades de desarrollo local. Memorias Encuentro Municipio, democracia y desarrollo local. Instituto del Conurbado. Universidad Nacional General Sarmiento. Argentina. pp. 12-21.

COMISIÓN DE DESARROLLO Y MEDIO AMBIENTE. (1987). Nuestro futuro común. Madrid: Alianza editorial.

COVIANDES. (2015). Coviandes. Recuperado de http://www.coviandes.com/nuestros-proyectos$2 /$.

DALY, H. (2001). La economía del estado estacionario. Lousiana State University.

DNP. (Junio de 2007). Agenda interna para la productividad y la competitividad. Recuperado de Ministerio de Comercio, Industria y Turismo:

http://www.mincit.gov.co/loader.php?|Servicio=Documentos\&IFuncion=verPdf\&id=23216\&nam e=InsumosAmazorinoquia. pdf\&prefijo=file.

ESPINEL, N. (1989). Villavicencio dos siglos de historia comunera 1740 - 1940. Villavicencio: Gráficas Juan XXIII.

ESTUPIÑÁN, L. (2012). Desequilibrios territoriales: estudio sobre la descentralización y el ordenamiento territorial Colombiano. Bogotá: Universidad del Rosario Editorial.

FAJARDO MONTAÑA, D. (1998). Colombia Orinoco. Bogotá: FEN Colombia.

FERRERO, A. M. (2010). Expansion urbana y sostenibilidad: una dicotomia dificil de conciliar. Revista Española de Control Externo, 5.

HARDOY, J. E. (1973). La forma de las ciudades coloniales en América Española. Revista de Indias, 33.

HARDOY, J. (s.f.). La forma de las ciudades coloniales en Hispanoamerica. pág. 1. Recuperado de https://catedrapernautfadu.files.wordpress.com/2015/06/ficha-bibliografica-nc2b08-la-formade-las-ciudades-coloniales.pdf 
JARAMILLO, C. G. (1997). José Hilario López y la expulsión de los jesuitas en 1850. Recuperado de http://www.banrepcultural.org/node/73391

MUNICIPAL, E. (2015). Diagnóstico Sectorial Suelo. Recuperado de http://181.49.19.3/ws/Documentos/ExpedienteMunicipal/Diagnostico-Sectorial-Suelo.pdf.

OJEDA, T. (2000). Villavicencio entre la documentalidad y la oralidad 1880 -1980. Villavicencio. Corocora orinoquense.

PIETRO, L. D. (2001). Hacia un desarrollo integrador equitativo: una introducción al desarrollo local. Argentina. Rescatado de

http://www.bibliotecavirtual.info/wpcontent/uploads/2011/06/hacia_un_desarrollo_integrador _y_equitativo.pdf.

PROGRAMA DE LAS NACIONES UNIDAS PARA EL DESARROLLO. (1998). Informe sobre desarrrollo humano.

RAUSCH, J. (2011). De pueblo de frontera a ciudad capital. Villavicencio: Juan XXIII Ltda.

RODRÍGUEZ, M. L. (2014). Aplicación de la legislación ambiental y territorial en municipios capitales: Estudio de caso Villavicencio (Colombia). Orinoquia vol.18 no.2 Meta.

RUEDA, S. (2009). La ciudad compacta y diversa frente a la cornubasión difusa. Recuperado de Biblioteca virtual. Ciudades para un futuro mas sostenible: http://habitat.aq.upm.

RUIZ, J. A. (2016). Antecedentes Plan de Ordenamiento Territorial. De Plan de Ordenamiento Territorial Villavicencio - Secretaría de Planeación Municipal. Villavicencio: Conferencia sobre POT Universidad de los Llanos.

SÁNCHEZ, F. J. (2007). El Desarrollo Sostenible: Un concepto de interés para la geografía. 157. Recuperado de http://www.ugr.es/ cuadgeo/docs/articulos/040/040-008.pdf.

SECRETARÍA DE PLANEACIÓN MUNICIPAL, Villavicencio. (2015). Documento Técnico soporte POT componente rural. Villavicencio, Colombia.

SECRETARÍA DE PLANEACIÓN MUNICIPIO DE VILLAVICENCIO. (2015). Documento de evaluación del plan de ordenamiento. Villavicencio.

SEPÚLVEDA, S. (2001). Desarrollo sostenible microregional. Bogotá, IICA.

TOVAR, A. C. (Marzo de 2015). Noticias IGAC. Recuperado de Departamento del Meta está valorizado en $\$ 18,7$ billones, según el IGAC: http://noticias.igac.gov.co/departamento-del-metaesta-valorizado-en-187-billones-segun-el-igac/.

URBANO LÓPEZ, B. (2013). Naturación urbana, un desafío a la urbanización. Chapingo, Serie Ciencias Forestales y del Ambiente Vol. 19, 225-235.

SECRETARÍA DE PLANEACIÓN MUNICIPAL . (2000). Plan de Ordenamiento Territorial año 2000. Clasificación del suelo, Art. 25. Clases de Suelos. Villavicencio. 
VOSTI, S. (2002). El rol de la agricultura en la salvación del bosque tropical. la agenda inconclusa: perspectiva para superar el hambre, la pobreza y la degradación ambienta.I Washington, Instituto internacional de investigación sobre políticas alimentaria.

WILSON, E. (2002). Urbanización y agricultura hacia el año 2020.la agenda inconclusa: perspectiva para superar el hambre, la pobreza y la degradación ambiental. Washington D.C. Instituto internacional de investigación sobre políticas alimentaria.

Trabalho enviado em 05 de setembro de 2017.

Aceito em 16 de outubro de 2017. 